\title{
Glycan-deficient PrP stimulates VEGFR2 signaling via glycosaminoglycan
}

\author{
Zhenxing Gao ${ }^{\mathrm{a}, \mathrm{d}}$, Huixia Zhang ${ }^{\mathrm{a}}$, Fei Hu${ }^{\mathrm{b}}$, Liheng Yang ${ }^{\mathrm{a}, \mathrm{d}}$, Xiaowen Yang ${ }^{\mathrm{c}}$, Ying \\ Zhu ${ }^{d}$, Man-Sun Sy, Chaoyang Lif,
}

\begin{abstract}
aUniversity of Chinese Academy of Sciences, Center for Molecular Virology, Wuhan Institute of Virology, Chinese Academy of Sciences, 44 Xiao Hong Shan Zhong Qu, Wuhan, 430071, China;

'Wuhan Brain Hospital, No.5 Huiji Road, Jiang'an district, Wuhan, 430010, China;

${ }^{\circ}$ Department of the First Abdominal Surgery, Jiangxi Tumor Hospital, Nanchang, 330029, China;

dDepartment of Virology, School of Life Sciences, Wuhan University, State Key Laboratory of Virology, Wuhan, 430072, China;
\end{abstract}

${ }^{\text {e}}$ Department of Pathology, School of Medicine, Case Western Reserve University, 2106 Cornell Road, Cleveland, OH, 44106, USA;

${ }^{f}$ Center for Molecular Virology, Wuhan Institute of Virology, Chinese Academy of Sciences, State Key laboratory of Virology; Wuhan Brain Hospital, 44 Xiao Hong Shan Zhong Qu, Wuhan, 430071, China.

"Corresponding author at: 44 Xiao Hong Shan Zhong Qu, Wuhan, 430071, China. E-mail address: cyli@wh.iov.cn (Chaoyang Li) 


\begin{abstract}
Whether the two N-linked glycans are important in prion, PrP, biology is unresolved. In Chinese hamster ovary ( $\mathrm{CHO}$ ) cells, the two glycans are clearly not important in the cell surface expression of transfected human PrP. Compared to fully-glycosylated PrP, glycan-deficient PrP preferentially partitions to lipid raft. In $\mathrm{CHO}$ cells glycan-deficient PrP also interacts with glycosaminoglycan (GAG) and vascular endothelial growth factor receptor 2 (VEGFR2), resulting in VEGFR2 activation and enhanced Akt phosphorylation. Accordingly, $\mathrm{CHO}$ cells expressing glycan-deficient PrP lacking the GAG binding motif or cells treated with heparinase to remove GAG show diminished Akt signaling. Being in lipid raft is critical, chimeric glycan-deficient PrP with CD4 transmembrane and cytoplasmic domains is absent in lipid raft and does not activate Akt signaling. $\mathrm{CHO}$ cells bearing glycan-deficient PrP also exhibit enhanced cellular adhesion and migration. Based on these findings, we propose a model in which glycandeficient PrP, GAG, and VEGFR2 interact, activating VEGFR2 and resulting in changes in cellular behavior.
\end{abstract}

Key words: PrP; GAG; N-linked glycosylation; lipid raft; VEGFR2 


\section{Introduction}

One of the most common protein post-translational modifications is $\mathrm{N}$-linked glycosylation. N-linked glycosylation is important in proper protein folding, transit to the cell surface and secretion, in a protein, as well as cell context dependent manner [1-4]. The normal human cellular prion protein, $\operatorname{PrP}$, is a widely expressed, highly conserved, glycosylphosphatidylinositol (GPI)-anchored cell surface glycoprotein [5-7]. The two N-linked glycosylation sites on human PrP are located at the C-terminus at residues 181 and 197. A plethora of more than 40 proteins have been reported to bind PrP [8]. In addition, PrP also binds divalent cations, such as copper and zinc, lipids, nucleic acids and GAG [9-12]. However, other than being essential for the pathogenesis of prion diseases, the normal functions of PrP remain obscure; $\operatorname{Prnp}^{-/-}$mouse is normal without apparent phenotype $[13,14]$. Whether the two glycans are important in PrP biology is debated. In some cell models, glycan-deficient PrP is retained in the cytosol, unable to reach the cell surface $[15,16]$. On the contrary, other studies find them to be dispensable for cell surface expression $[17,18]$. Even though the two Nlinked glycans are not essential for the pathogenesis of prion diseases, they do contribute to disease phenotypes as well as strain specificity of some infectious prion [19-22]. However, the underlying mechanisms by which $\mathrm{N}$-linked glycans modulate disease phenotype or strain specificity are not known.

Because of these ambiguities, we investigated whether the two $\mathrm{N}$-linked glycans were important in PrP biology using $\mathrm{CHO}$ cell, which lacked detectable endogenous hamster PrP [23]. We transfected a wild type (WT) human PrP; a single glycan site mutant (SM) PrP, in which one of the glycosylation sites, asparagine $(\mathrm{N})$ 181, was altered to an alanine $(\mathrm{A})(\mathrm{N} 181 \mathrm{~A})$; another SM PrP, in which the other site, N197, was mutated to an A (N197A); a double mutant (DM) PrP, in which both sites were replaced with $\mathrm{A}$ individually into $\mathrm{CHO}$ cells. These mutated PrP are collectively referred to as glycan-deficient PrP. We find that all glycan-deficient PrP are expressed on the cell surface in levels comparable to WT PrP. However, glycan-deficient PrP appears to partition more in lipid raft than 
wild-type PrP. Furthermore, glycan-deficient PrP forms complex with VEGFR2 and GAG resulting in the activation of VEGFR2 and the PI3K-Akt signaling pathway. These biochemical alterations also resulted in changes in cellular behavior; compared to cells with wild type PrP, cells with glycan-deficient PrP are more adhesive and more mobile. Collectively, these results suggest that in $\mathrm{CHO}$ cells, one of the functions of $\mathrm{N}$-linked glycans on $\operatorname{PrP}$ is to negatively regulate PrP functions.

\section{Materials and methods}

\subsection{Cell lines}

Chinese hamster ovary $(\mathrm{CHO})$ cell line was kindly provided by Dr. Pamela Stanley of Albert Einstein College of Medicine, New York City, NY [24]. The cells were cultured with Minimum Essential Medium Alpha (11900024, Gibco), 1\% antibiotic Penicillin-Streptomycin solution (PS) (03-031-1, Biological Industries) plus $10 \%$ fetal bovine serum (FBS) (04-001-1, Biological Industries). The pgsA745 cell line was purchased from ATCC (CRL-2242), the cells were cultured with F-12K Medium (30-2004, ATCC) plus 10\% FBS and 1\% PS as suggested by the vendor. All cells were cultured in a $37^{\circ} \mathrm{C}, 5 \% \mathrm{CO}_{2}, 95 \%$ humidity incubator (Series 8000 WJ, Thermo Scientific).

\subsection{Antibodies and other reagents}

Anti-PrP Mabs 4H2 and 7A12 were produced, purified, characterized and biotinylated as reported by us [25, 26]. Antibodies against phospho (p)-Akt (Ser473) (4060), Akt (4691), p-SAPK/JNK (4668), SAPK/JNK (9252), HRP linked goat anti-mouse IgG (7076), HRP linked goat anti-rabbit IgG (7074), and LY294002 (9901) were purchased from Cell Signaling Technology. Antibodies against VEGFR2 (Flk-1) (sc-505), p-VEGFR2 (p-Flk-1) (sc-101820), flotillin-1 (sc25506) and Protein A/G PLUS-Agarose (sc-2003) were purchased from Santa 
Cruz Biotechnology. Heparin antibody (MAB2040) was purchased from Merck Millipore. Receptor tyrosine kinase (RTK) inhibitors AG490 (S1143), Axitinib (S1005), BGJ398 (S2183), BMS754807 (S1124), Crizotinib (S1068), Ki8751 (S1363), Mubritinib (S2216), RGD peptides (S8008), SAR131675 (S2842), ZM306416 (S2897) were purchased from Selleck Chemicals (Texas, USA). Heparinase I and III (H3917) were purchased from Sigma. Proteinase inhibitor cocktail (11697498001) and 4', 6-diamidino-2-phenylindole (DAPI) (10236276001) were purchased from Roche. Alexa Fluor 555 conjugated goat anti-rabbit IgG (A21429), Alexa Fluor 555 conjugated goat anti-mouse IgG (A-21424), Alexa Fluor 647 conjugated goat anti-mouse IgG (A-21235), Alexa Fluor 647 conjugated streptavidin (S-21374), and Lipofectamine 2000 transfection reagent (11668-019) were purchased from Invitrogen. EZ-link Sulfo-NHS-Biotinylation kit (21425) was purchased from Thermo scientific. All the other chemicals were purchased from Amresco (OH, USA).

\subsection{Construction of different human PrP mutants}

Cloning vector pHAGE-CMV-MCS-IZsGreen and the packaging plasmids psPAX2, pMD2.G were kindly provided by Prof. Zan Huang (Wuhan University). Wild type human PRNP (hPrP) DNA was created as described [27]. Constructions of hPrP-N181A, hPrP-N197A, hPrP-N181A-N197A (double mutation, hPrP-DM), and hPrP-DM- $\triangle$ KKRPK were made by Site-directed Gene Mutagenesis Kit (D0206, Beyotime, Shanghai, China). For the constructions of different PrPs-CD4 chimeric proteins, human CD4 transmembrane domain and cytosol tail was amplified with the indicated primer pairs (Table S1) containing restriction enzyme Bsp119 I site before the GPI-anchor signal sequence in the forward primer, and restriction enzyme BamH I site in the reverse primer. The site of Bsp119 I was deleted after CD4 transmembrane and cytosol domain was inserted into the PrP expressing constructs. All the constructs were sequence confirmed. 


\subsection{Expression of human PrP in $\mathrm{CHO}$ cells}

Wild type and mutant PrP were inserted in the pHAGE-CMV-MCS-IZsGreen vector and transfected into 293T cells as described [28, 29]. Lentiviral particles were collected by centrifuging at $700 \times g$ for 10 minutes, and filtered with $0.45 \mathrm{~nm}$ filter. $\mathrm{CHO}$ or pgsA-745 cells were then infected with the virions for 6 hours. PrP expression was confirmed by immunofluorescent staining followed by flow cytometric analysis.

\subsection{Co-immunoprecipitation (Co-IP)}

PrP expressing cells were seeded in culture medium at $37^{\circ} \mathrm{C}, 5 \% \mathrm{CO}_{2}, 95 \%$ humidity for 14 hours. The cells were cultured for an additional 24 hours in medium without FBS. After that cells were lysed in cell lysis buffer $(20 \mathrm{mM}$ Tris$\mathrm{HCl}$ ( $\mathrm{pH}$ 7.5), $150 \mathrm{mM} \mathrm{NaCl}, 1 \mathrm{mM} \mathrm{Na} \mathrm{N}_{2}$ EDTA, $1 \mathrm{mM}$ EGTA, $2.5 \mathrm{mM}$ sodium pyrophosphate, $1 \mathrm{mM}$ b-glycerophosphate, $1 \mathrm{mM} \mathrm{Na}_{3} \mathrm{VO}_{4}, 1 \%$ Triton, $1 \mathrm{mM}$ PMSF and $1 \times$ proteinase inhibitor cocktail) and protein concentration was quantified using a Bio-Rad Protein Assay (500-0002, Bio-Rad). Before co-IP, cell lysate were pre-cleared with rabbit IgG and protein $A / G$ agarose beads for 1hour at $4^{\circ} \mathrm{C}$. Pre-cleared lysate were incubated with $2 \mu \mathrm{g}$ of indicated antibodies at $4^{\circ} \mathrm{C}$ for 14 hours. The protein $A / G$ agarose beads were then added for an additional 3 hours and incubated at $4^{\circ} \mathrm{C}$. After washing 6 times with cell lysis buffer, the beads were collected by centrifuging at $1000 \times g$ for 1 minute. $30 \mu 1.3 \times$ reducing sample loading buffer (10\% sucrose (W/V), 5\% 2-mercaptoethanol (V/V), 2\% SDS (W/V), $0.0625 \mathrm{M}$ Tris-HCl pH 6.8, 0.0004\% bromophenol blue (W/V)) were then added to the beads. Proteins co-purified with VEGFR2 were subjected to immunoblotting.

\subsection{Immunoblotting}


Cultured cells were harvested, lysed, and cell lysate prepared as described by us [28]. The concentration of proteins was measured by Bio-Rad Protein Assay (500-0002, Bio-Rad). Comparable levels of proteins were loaded and separated on $10 \%$ SDS-PAGE gel. After electrophoresis, proteins were transferred to a nitrocellulose membrane (HATF00010, Merck Millipore) and blocked in 3\% BSA in TBST (137 mM NaCl, $20 \mathrm{mM}$ Tris, $0.1 \%$ Tween-20, pH 7.6) overnight at $4{ }^{\circ} \mathrm{C}$. To detect the proteins on nitrocellulose membrane, the blots were first probed with the primary antibody. Bound primary antibodies were then probed with a HRP-conjugated secondary antibody. The concentration of anti-PrP antibodies $4 \mathrm{H} 2$ was $1 \mu \mathrm{g} / \mathrm{ml}$. All the other primary antibodies were used according to the manufacturer's instruction.

PNGase $F$ (P0704S, NEB) treatment of PrP was performed according to manufacturer's instruction. Briefly, $20 \mu \mathrm{g}$ proteins per sample were combined with $1 \mu \mathrm{l} 10 \times$ glycoprotein denaturing buffer and deionized water to make a $10 \mu \mathrm{l}$ reaction volume on ice. The sample was then boiled for 10 minutes, and $2 \mu \mathrm{l} 10 \times$ G7 buffer, $2 \mu \mathrm{l}$ 10\% NP40, $5 \mu$ l deionized water and $1 \mu$ PNGase F were added to make a total of $20 \mu \mathrm{l}$ reaction. PNGase F treated samples were then subjected for immunoblotting as above.

\subsection{Cell surface biotinylation}

Cell surface biotinylation was performed according to manufacturer's protocol (21331, Thermo scientific). After protein biotinylation, the biotin conjugated proteins were pulled down with streptavidin beads (N-1000, Solulink). Proteins were further separated with $10 \%$ SDS-PAGE gel and immunoblotted with $4 \mathrm{H} 2$ accordingly. The amount of unglycosylated, mono-glycosylated, and diglycosylated PrP were quantified based on densitometry using the Image $\mathrm{J}$ software $(\mathrm{NIH})$.

\subsection{Immunofluorescence staining}


CHO cells expressing WT-PrP, N181A-PrP, N197A-PrP, or DM-PrP were cultured as described in above. To detect PrP expression, cells were detected with Mab $4 \mathrm{H} 2(10 \mu \mathrm{g} / \mathrm{ml})$ at $4{ }^{\circ} \mathrm{C}$ for 1 hour. Bound antibodies were detected with Alexa Fluor 555 conjugated goat anti-mouse antibody $(1 \mu \mathrm{g} / \mathrm{ml})$ for 1 hour at $4{ }^{\circ} \mathrm{C}$.

For double labeling of PrP (GPI anchored and CD4 chimeric PrP) and GM1, the cells were seeded as above. GM1 was labeled with the Vybrant lipid raft labeling kits (V-34404, Molecular Probes) according to the manufacturer's instructions. Briefly, cells were incubated with medium plus Alexa Fluor 555 conjugated CT-B $(1 \mu \mathrm{g} / \mathrm{ml}) 10$ minutes at $4{ }^{\circ} \mathrm{C}$. 200-fold dilution of anti-CT-B antibodies were then added to crosslink the CT-B labelled lipid rafts. PrP was detected with Mab 4H2 $(10 \mu \mathrm{g} / \mathrm{ml})$ as described above. Mouse lgG1 or rabbit IgG isotype control were used as negative controls. Nuclei were counter stained with DAPI. Images were taken with A1 MP+ multiphoton confocal microscope (model, IMA101065ALS, Nikon) after adding anti-fade mounting media (P0128, Beyotime). Co-localization of PrP and GM1 was counted from 30 cells in 11 randomly selected images. Pearson's correlation was used to show the colocalization according to NIS-Elements AR instruction.

For double labeling of PrP and VEGFR2, cells were cultured as described in above. Rabbit polyclonal antibody specific for VEGFR2 (5 $\mathrm{gg} / \mathrm{ml})$ and Mab $4 \mathrm{H} 2$ $(10 \mu \mathrm{g} / \mathrm{ml})$ were applied to culture medium at $4{ }^{\circ} \mathrm{C}$ for 1 hour. After extensive washing to remove unbound antibody, bound primary antibodies were probed with Alexa Fluor 555 conjugated goat anti-rabbit IgG $(1 \mu \mathrm{g} / \mathrm{ml})$ or Alexa Fluor 647 conjugated goat anti-mouse $\operatorname{lgG}(1 \mu \mathrm{g} / \mathrm{ml})$ for 1 hour at $4^{\circ} \mathrm{C}$. Mouse $\lg \mathrm{G} 1$ or rabbit $\lg G$ isotype control were used as negative controls. Images were taken as described in above.

For double labeling of PrP and heparin, anti-heparin Mab (10 $\mu \mathrm{g} / \mathrm{ml})$ was added to cultured cells at $4^{\circ} \mathrm{C}$ for 1 hour. Bound antibody was probed with Alexa Fluor 555 conjugated goat anti-mouse $\operatorname{lgG}(1 \mu \mathrm{g} / \mathrm{ml})$. Mouse lgG1 isotype control was used to block extra goat antibodies. PrP was then detected with bio-4H2 (10 
$\mu \mathrm{g} / \mathrm{ml}$ ) for 1 hour at $4^{\circ} \mathrm{C}$. Bound biotin was then probed with Alexa Fluor 647 conjugated streptavidin $(1 \mu \mathrm{g} / \mathrm{ml})$. Images were taken as described in above.

\subsection{Flow cytometry staining of cell surface PrP}

Cells in tissue culture flasks were treated with 25 mM EDTA (0105, Amresco) diluted in PBS ( $\mathrm{pH} \mathrm{7.6)}$ for 3 minutes to release the cells. Single cell suspension was centrifuged at $200 \times g$ for 3 minutes at $4^{\circ} \mathrm{C}$. The collected cells were washed twice with ice cold PBS then incubated with Mabs $4 \mathrm{H} 2$ or $7 \mathrm{~A} 12$ at $10 \mu \mathrm{g} / \mathrm{ml}$ diluted in PBS for 30 minutes on ice. Bound antibodies were detected with the APC conjugated goat anti-mouse $\operatorname{lgG}(405308$, BioLegend) at $2 \mu \mathrm{g} / \mathrm{ml}$ for an extra 30 minutes at $4{ }^{\circ} \mathrm{C}$. Bound secondary antibodies were analyzed with the FACSAria III (model, 648282, BD Biosciences). Mouse IgG1 was applied as a negative control or antibody stained empty vector transfected cells was applied as a negative control.

\subsection{RNA interference of hamster VEGFR2}

SiRNAs specific for hamster VEGFR2 were listed in Table S2. The sequences were designed by online software siDESIGN Center (GE Dharmacon, CO, USA), and synthesized by GenePharma (Shanghai, China). The cells were seeded 14 hours at $37^{\circ} \mathrm{C}, 5 \% \mathrm{CO}_{2}, 95 \%$ humidity, $\mathrm{CHO}$ cells expressing $\mathrm{PrP}$ were transfected with siRNAs by lipofectamine 2000 in the absence of FBS for 6 hours. Cells were then cultured in medium with 10\% FBS for 24 hours before replacing with serum free medium for additional 24 hours for signal transduction assays. Cell lysate were prepared for immunoblotting as described by us [28]. Relative expression level was quantified using Image $\mathrm{J}$ software $(\mathrm{NIH})$.

\subsection{Lipid raft assays}


Lipid raft fractionation was performed as described [28]. Briefly, the cells were cultured in $10 \mathrm{~cm}$ petri dish (310109011,Thermo Fisher) at $37^{\circ} \mathrm{C}, 5 \% \mathrm{CO}_{2}, 95 \%$ humidity and then lysed in Mes-buffered saline $(25 \mathrm{mM}$ Mes, $150 \mathrm{mM} \mathrm{NaCl}, \mathrm{pH}$ 6.5) containing $1 \%$ Triton $X-100$ plus $1 \mathrm{mM}$ PMSF and $1 \times$ proteinase inhibitor cocktail. A $1 \mathrm{ml} 40 \%$ of lysate was made by adding $0.5 \mathrm{ml}$ lysate with equal volume of $80 \%$ sucrose in Mes-buffered saline. Three $\mathrm{ml} 30 \%$ sucrose in Mesbuffered saline were then loaded on top of the $40 \%$ fraction. Finally, $1 \mathrm{ml} 5 \%$ sucrose in Mes-buffered saline was placed on the top. The samples were centrifuged at $180,000 \times g$ in an SW-55 rotor (Beckman) for 17 hours at $4^{\circ} \mathrm{C}$. Sucrose gradients were collected as $500 \mu \mathrm{l}$ per fractions from the top to the bottom. Proteins in each fraction were separated on 10\% SDS-PAGE gel and immunoblotted with indicated antibodies.

\subsection{Signaling transduction assays}

To detect signal transduction alteration due to different PrP expression or heparinase or drug treatment, the cells were first cultured 14 hours in medium supplemented with $10 \%$ FBS. In the case of drug treatment, cells were then cultured in medium without FBS for an additional 24 hours before making cell lysate, or cells were cultured in medium without FBS for 24 hours but drugs at specified concentrations were added in culture medium 2 hours before making cell lysate. In the case of heparinase treatment, cells were cultured in medium without FBS for 24 hours but heparinase at specified concentration was added in culture medium 4 hours before making cell lysate. Cell lysate were made as described in above. Proteins were then separated on 10\% SDS-PAGE gel and transferred on a nitrocellulose membrane. Target molecules were probed with specific antibodies according to manufacturer's instruction.

\subsection{Cell adhesion assays}


Cells were treated with $0.25 \%$ trypsin-EDTA for 30 seconds in incubator and then were shaken vigorously to detach from the culture flask. Digested cells were immediately mixed with culture medium containing $10 \%$ FBS to neutralize trypsin enzymatic activity and then centrifuged at $200 \times g$ for 5 minutes. Single cell suspension was reconstituted with medium. $1 \times 10^{4} \mathrm{PrP}$ expressing cells were seeded in heparin coated glass bottom culture dishes for 15 minutes, the nonadhesion cells were aspirated off and adherent cells were fixed at $4 \%$ paraformaldehyde. Adherent cells were counted with microscopy.

\subsection{Cell migration assays}

Cells were cultured in a 6 well plate till 100\% confluency and then the medium was replaced with new medium without FBS. Wound was created with a tip-cut $200 \mu \mathrm{l}$ pipette tip. The wound areas were photographed at 6,12 and 24 hours after wound creation. Image $\mathrm{J}(\mathrm{NIH})$ software was applied to quantify the wound healing areas. Briefly, based on Image $J$, the readings (A) of newly created wound areas as one hundred percent, after the indicated time points post wound infliction, un-wound area readings $(B)$ were quantified, and the healing ratio was calculated as $1-\mathrm{B} / \mathrm{A}$.

\subsection{Statistical analyses}

All of the experiments were repeated at least 3 times and analyzed by student's t-test; quantitative data are expressed as the mean and standard error of the mean. $p<0.05$ was considered statistically significant.

\section{Results}

3.1. The two N-linked glycans on PrP are not essential for the expression of PrP on the cell surface of $\mathrm{CHO}$ cells 
The epitopes of the anti-PrP Mabs and the location of the glycosylation sites are shown in Fig. 1A. We use flow cytometry to enrich for PrP expressing stable cell lines transfected with WT, N181A, N197A, or double mutant (DM) PrP. Cells were stained with anti-PrP Mabs, $4 \mathrm{H} 2$ or $7 \mathrm{~A} 12$ to show that all cell lines have comparable cell surface PrP level (Fig. 1B). Immunofluorescence staining and confocal imaging analysis reveal the expression of various $\operatorname{PrP}$ isoforms at comparable levels on the cell surface (Fig. 1C). By immunoblotting using Mab $4 \mathrm{H} 2$, majority of WT PrP is di-glycosylated (DG), most of the N181A and N197A are mono-glycosylated (MG), and the DM is unglycosylated (UG) (Fig. 1D). After PNGase $F$ treatment, all four proteins migrate as UG PrP (Fig. 1E). Hence, the $\mathrm{N}$-linked glycans are not required for human PrP expression on the cell surface.

\subsection{Glycan-deficient PrP partitions more in lipid raft than di-glycosylated PrP}

Like other GPI-anchored proteins, PrP is found in lipid rafts [30, 31]. N-linked glycans are highly negative charged, and thus repulsive [1-4]. Therefore, we next investigated whether $\mathrm{N}$-linked glycans influence the partition of $\operatorname{PrP}$ in lipid rafts. More DM PrP was found in the lipid raft fractions (fractions 3-5), based on densitometry the amount ranged from 30 to $45 \%(n=6)$ of the total PrP. In contrast, between 10 to $15 \%(n=6)$ of the total WT PrP was found in the lipid raft fractions (Fig. 2A, B). Accordingly, proportionally less DM PrP was observed in non-lipid raft fractions compared to WT PrP (Fractions 8-10). We use flotillin-1, a lipid raft associated protein as a control. The levels of flotillin-1 in the lipid raft were comparable between the DM and WT cells (Fig. 2A, comparing panels 1 and 3), indicating that the difference is limited to $\operatorname{PrP}$.

Ganglioside, GM1, is a major lipid raft component [32]. Cholera toxin binds GM1, and is used extensively to visualize lipid rafts on the cell surface [33, 34]. Therefore, we use two-color immunofluorescence staining to determine whether more DM PrP is co-localized with GM1 on the cell surface. We found that there was more co-location of PrP and GM1 on the surface of DM cells compared to 
WT cells (Fig. 2C). Pearson's correlation between PrP and GM1 is significantly higher for DM PrP and GM1 than for WT PrP and GM1 (Fig. 2D).

\subsection{Cells bearing glycan-deficient PrP activate signaling involving VEGFR2 and} GAG

Some cell surface receptors, such as VEGFR, bFGFR and TGF $\beta$ R require GAG for optimal signaling [35-37]. It is also known that PrP can bind cell surface GAG [38] and binding requires the presence of KKRPK at the N-terminus of PrP [39]. We thus investigate whether the presence of glycan-deficient PrP modulates cell signaling in the respective cell lines. We also delete KKRPK ( $\triangle K K R P K)$ on $\operatorname{PrP}$ to investigate if this domain is involved in the signaling. Unexpectedly, when cells were cultured in FBS free condition, the glycan-deficient PrP cell lines consistently have higher levels of $p$-Akt (S473) compared to cells expressing WT PrP (Fig. 3A, top two panels). This enhancement requires the KKRPK motif of $\operatorname{PrP}$, which is essential for PrP to bind GAG [39]. In cells expressing similar level of cell surface DM- $\triangle$ KKRPK PrP (Fig. S1), the increase of p-Akt was absent (Fig. $3 \mathrm{~A}$, last lane of panels 1 and 2). We did not detect any significant changes in the levels of a number of other signaling molecules, such as p-JNK (Fig. 3A, panels 3 and 4).

The PI3 kinase is required for the production of PIP3 from PIP2 to target Akt to the cell surface [40-42]. To seek additional support for our conclusion that the activation of $\mathrm{p}-\mathrm{Akt}$ is $\mathrm{PI} 3 \mathrm{~K}$ dependent, we treated the PrP expressing $\mathrm{CHO}$ cells with LY294002, an inhibitor of PI3 kinase, we used cells treated with DMSO as negative controls. We found that cells treated with LY294002 but not DMSO had significantly reduced p-Akt level (Fig. 3A, bottom two panels). Thus, glycandeficient PrP can initiate PI3K-Akt signaling in an autocrine mode, without exogenous signal.

Some receptor tyrosine kinases depend on p-Akt for downstream signaling [40, 41]. We used a panel of tyrosine kinase inhibitor to identify the receptor that is responsible for enhanced p-Akt. We found Axitinib and Ki8751 consistently 
inhibited the p-Akt signaling (Fig. 3B, panels 1, 2 and panels 5, 6). Since Axitinib (an inhibitor for VEGFR, PDGFR, or c-Kit) and Ki8751 (an inhibitor for VEGFR2) significantly reduce p-Akt level whereas ZM306416 (an inhibitor for VEGFR1) and SAR 131675 (an inhibitor for VEGFR3) do not alleviate phosphorylation of Akt (Fig. 3B, panels 3, 4 and panels 7, 8), we posit that VEGFR2 is likely to be the receptor engaged. The other tested inhibitors, such as AG490, BGJ398, BMS754807, Crizotinib, Mubritinib, and RGD did not show inhibitory effect (Fig. $3 C)$.

CHO cells are known to express VEGFR2 and produce VEGF [43]. We then investigated whether PrP and VEGFR2 were co-localized. We found that more PrP immunoreactivity was associated with VEGFR2 in cells with glycan-deficient PrP than in cells with WT PrP (Fig. 4A). This observation was further confirmed by co-IP experiments. We found that an anti-VEGFR2 antibody brought down much more unglycosylated PrP from N181A and DM cells compared to PrP from WT and DM- $\triangle$ KKRPK cells (Fig. 4B, upper panels). Control antibody did not pull down unglycosylated PrP under the same condition (Fig. S2). Since KKRPK domain is required for binding between PrP and GAG, this result provide additional evidence that the interaction between glycan-deficient $\operatorname{PrP}$ and VEGFR2 is mediated by GAG. Furthermore, in cells with glycan-deficient PrP there is more p-VEGFR2, indicating the activation of the receptor (Fig. 4B, bottom panels).

The involvement of VEGFR2 in this signaling scheme was further confirmed by siRNA knocking-down of VEGFR2 in DM PrP expressing CHO cells. These cells show reduced level of p-Akt (Fig. 4C). Collectively, these results suggest that glycan-deficient PrP, GAG and VEGFR2 work in concert to promote the phosphorylation of Akt.

To further prove GAG is mediating the signaling cascade, we double stained PrP and heparin, a GAG. We found a close association between glycan-deficient PrP and heparin (Fig. 5A). Furthermore, when glycan-deficient PrP cells were treated with heparinase, the levels of $p$-Akt were reduced (Fig. 5B, C). We posit 
that such a reduction in p-Akt level after heparinase treatment is due to a reduced PrP-GAG interaction.

Additional evidence supporting a role for GAG in this signaling scheme came from experiments using the pgsA-745 cell line, which is a $\mathrm{CHO}-\mathrm{K} 1$ derived cell line deficient in GAG synthesis [44]. We transfected WT PrP or DM PrP into this cell line and selected transfected cells with similar surface PrP expression by flow cytometry (Fig. 5D, left panel). Immunoblotting confirmed that the PrP expression is similar for WT PrP and DM PrP in these cells (Fig. 5D, right panel). However, expression of DM PrP in pgs-745 cell line did not up-regulate p-Akt (Fig. 5E), thus supporting that GAG is required for activation of PI3K-Akt pathway in $\mathrm{CHO}$ cells expressing glycan-deficient PrP.

3.4. Being GPI-anchored and in lipid rafts are essential for PrP to participate in signaling

Since receptor tyrosine kinase activation requires lipid raft localization [45, 46], we then investigated whether being GPI anchored and in lipid raft were important for glycan-deficient PrP to participate in activating VEGFR2. We generated different chimeric PrP proteins containing the extracellular domain of PrP fused to the transmembrane and cytoplasmic domains of human CD4 (Fig. 6A). We then selected for cells with similar level of surface PrP by flow cytometry using $4 \mathrm{H} 2$ Mab (Fig. 6B). Immunoblotting showed that those chimeric PrP-CD4 and GPI anchored-PrP cells appear to express comparable level of PrP (Fig. 6C). However, the co-location of DM-CD4 and GM1 is reduced compare to DM PrP and GM1 (Fig. 6D). Correspondingly, much less DM-CD4 protein is present in the lipid raft fractions (Fig. 6E, fractions 3-5). More importantly, the enhancements of p-Akt levels were significantly diminished in cells bearing glycan-deficient chimeric CD4-PrP (Fig. 6F, G). These results are consistent with our hypothesis that being GPI anchored and localizing in lipid raft are important for glycandeficient PrP to participate in the activation of VEGFR2 signaling. 
3.5. Cells bearing Glycan-deficient PrP are more adhesive and migratory in vitro

Finally, we investigated the biological consequences of expressing glycandeficient PrP with enhanced Akt phosphorylation in $\mathrm{CHO}$ cells. $\mathrm{CHO}$ cells with glycan-deficient PrP are more adhesive (Fig. 7A) and migrate faster in a wound healing assay compared to cells with WT PrP (Figs. 7B and S3). Accordingly, the enhanced motility also requires the presence of GAG binding domain, KKRPK, in the N-terminus of DM PrP.

\section{Discussion}

Whether the two highly conserved $\mathrm{N}$-linked glycans are important in the expression of PrP on the cell surface is controversial [15-18]. Based on the results presented here, it is clear that the glycans are not essential for the expression of human PrP on the surface of $\mathrm{CHO}$ cells (Fig. 1B, C). While most of the glycan-deficient PrP species migrated according to their molecular masses in SDS-PAGE, the single mutant N181A appears to migrate a bit faster than the other single mutant, N197A (Fig. 1D, E). The reason for this discrepancy is not known. However, this motility difference in SDS-PAGE cannot account for the results seen in all subsequent experiments. All glycan-deficient PrP, including N181A, show comparable results (Figs 3 and $6 \mathrm{~F}$ ).

Earlier studies suggested that GPI-anchored proteins exist in the cell membrane as small aggregates composing from 4 to $15 \mathrm{GPI}$ anchored proteins $[47,48]$. In CHO cells, more glycan-deficient PrP is found in lipid raft (Fig. 2). We envision that without the negatively charged, repulsive glycans on PrP, more PrP are packed in the lipid raft. If our hypothesis is correct, the lipid raft should accommodate more glycan-deficient GPI anchored proteins. Prion infection requires the presence of $\mathrm{PrP}^{\mathrm{SC}}$ in lipid raft [49], which may convert lipid raft associated $\mathrm{PrP}^{\mathrm{C}}$ on cell surface [50]. Our results thus support the cell model of PrP infection that unglycosylated PrP promotes accumulation of $\mathrm{PrP}^{\mathrm{SC}}$ in cultured cells [16]. 
Most interestingly, expression of glycan-deficient $\mathrm{PrP}$ in $\mathrm{CHO}$ cells enables $\mathrm{CHO}$ cells to initiate autocrine signaling involving PrP, GAG and VEGFR2 (Figs 3, 4 and 5). This interpretation is supported by multiple lines of evidence: 1) $\mathrm{CHO}$ cells expressing DM- $\triangle K K R P K$ PrP, which is unable to bind GAG is unable to upregulate p-Akt (Fig. 3) ; 2) PrP, VEGFR2 and GAG are physically co-localized in lipid rafts(Figs. $4 A, B$ and $5 A$ ); 3) down regulation of VEGFR2 by shRNAi in glycan-deficient cells reduces signal transduction(Fig. 4C); 4) treatment of DM PrP expressing cells with heparinase to remove GAG, reduces the levels of signaling(Fig. 5B, C); 5) expressing DM PrP in GAG deficient pgsA-745 cells does not show increase in PI3K-Akt signaling compare to WT PrP expressing pgsA-745 cells (Fig. 5D, E).

All CHO cells bearing glycan-deficient PrP (N181A, N197A and DM) show enhanced p-Akt signaling. However, by co-IP, VEGFR2 pulls down only UG PrP but not MG PrP. The reason for this discrepancy is not clear. As determined by cell surface biotinylation, less than $5 \%$ of the total WT PrP on the cell surface is unglycosylated whereas on the cell surface the amount of UG PrP is increased to about 15 to $20 \%$ in the MG PrP (Fig. S4). VEGFR2 may interact preferentially with UG PrP; the reason that cells bearing MG PrP also show enhanced signaling is due to the proportional increase in the level of UG PrP on the cell surface.

Furthermore, it appears that the levels of p-Akt are comparable between cells bearing MG PrP and UG PrP, suggesting that the VEGFR2 signaling has reached plateau. We posit that the limiting factor may be the levels of VEGFR2 expression in $\mathrm{CHO}$ cells. While we were able to consistently pull down PrP using anti-VEGFR2 antibody, we were unable to reliably pull down VEGFR2 using antiPrP antibody; indicating that the level of PrP is much higher than that of VEGFR2 in $\mathrm{CHO}$ cells.

The detail mechanism responsible for initiating this signaling cascade has not been established. The half-life of VEGFR2 on the cell surface is important in regulating VEGFR2 signaling (52-54). Bridging by GAG that is anchored by glycan-deficient PrP may alter the half-life of cell surface VEGFR2. Furthermore, 
since VEGF also binds GAG, cells surface GAG may be able to trap and concentrate VEGF, enabling VEGFR2 to respond to lower levels of VEGF. In addition, GAG can bring together VEGFR2 in cells that express low levels of VEGFR2, thus facilitating the signaling. Being GPI-anchored is also important for signaling. Glycan-deficient PrP bearing a transmembrane and cytoplasmic domain of CD4 does not localize in the lipid raft and shows reduced p-Akt signaling compared to GPI anchored glycan-deficient PrP (Fig. 6).

VEGFR2 promotes cellular survival, migration and differentiation, and actin cytoskeleton organization [51,52]. Our observations that $\mathrm{CHO}$ cells bearing glycan-deficient PrP are more adhesive and migratory are consistent with the known functions of VEGFR2. Based on these observations, we propose a model to account for the observations reported here (Fig. 7C). In this model, glycandeficient PrP with its N-terminal KKRPK domain can bind more cell surface GAG and VEGFR2 thus activating VEGFR2 signaling. However, when the N-linked glycans are fully present, they somehow prevent the binding of the KKRPK domain to cell surface GAG, thus inhibiting the VEGFR2 activation.

The exact nature of the GAG on the cell surface that facilitates $\operatorname{PrP}$ and VEGFR2 signaling is not known. The anti-heparin Mab used in this study reacts with both heparin and heparan sulfate. The heparinase preparation used also contains both heparinase and heparanase. Additional biochemical studies will be needed to identify whether the GAG in this scheme is free GAG or proteoglycans associated GAG on the cell surface.

All our experiments were carried out in $\mathrm{CHO}$ cells. Whether our conclusions have in vivo significance remains to be determined. During normal aging in mice, the proportion of under glycosylated PrP increases [53]. PrP is also glycosylated differently in different cell types $[54,55]$. In human prion diseases, the ratios of $D G, M G$ and UG PrP have long been considered to be important in the classification of human prion diseases [56, 57]; different PrP glycoforms may contribute to different aspects of the disease phenotype [19-21]. It has been reported that prion infection/conversion occurs in lipid raft $[49,50]$. In cell model of PrP infection, unglycosylated PrP promotes accumulation of infectious prion in 
cultured cells [16]. Our finding that more glycan-deficient PrP are detected in lipid raft may provide an explanation for these findings. Finally, congenital disorder of glycosylation is a group of more than 75 human diseases, including immune deficiencies, inflammation, development as well as metabolic abnormalities [5860]. Aberrant protein glycosylation also contributes to tumor biology [61]. Any defects in glycosylation may alter the proportion of under glycosylated PrP contributing to pathogenesis.

\section{Acknowledgments}

This work was supported by grants from Chinese National Science Foundation (81172376, 31270209), Nature Science Foundation of Hubei Province (2015CFA087), Chinese Academy of Sciences (100-Talents Program), State Key Laboratory of Virology of China (2015IOV005), WIV "One-Three-Five" Strategic Programs.

We also thank Mr. Haojie Hao for scientific illustration of the proposed model. We thank The Core Facility and Technical Support, Wuhan Institute of Virology for technique support in Confocal Microscopy (Dr. Gao) and Flow Cytometry (Ms. Min).

\section{Competing interests}

The authors declare that they have no conflicts of interest with the contents of this article.

\section{Author contributions}

Z. G. and C. L. designed the research; Z. G. and C. L. performed the experiments; Z. G., H. Z., F. H., L. Y., X. Y., Y. Z., M. S., and C. L. analyzed the data and contributed reagents; Z. G., M. S., and C. L. wrote the paper. 


\section{References}

[1] N. Mitra, S. Sinha, T.N. Ramya, A. Surolia, N-linked oligosaccharides as outfitters for glycoprotein folding, form and function, Trends Biochem Sci 31(3) (2006) 15663.

[2] A. Helenius, M. Aebi, Roles of N-linked glycans in the endoplasmic reticulum, Annu Rev Biochem 73 (2004) 1019-49.

[3] A. Tannous, G.B. Pisoni, D.N. Hebert, M. Molinari, N-linked sugar-regulated protein folding and quality control in the ER, Seminars in cell \& developmental biology 41 (2015) 79-89.

[4] A. Varki, Biological roles of oligosaccharides: all of the theories are correct, Glycobiology 3(2) (1993) 97-130.

[5] S.B. Prusiner, Prions, Proceedings of the National Academy of Sciences of the United States of America 95(23) (1998) 13363-83.

[6] D.A. Harris, Cellular biology of prion diseases, Clinical microbiology reviews 12(3) (1999) 429-44.

[7] J. Collinge, Prion diseases of humans and animals: their causes and molecular basis, Annual review of neuroscience 24 (2001) 519-50.

[8] R. Linden, V.R. Martins, M.A. Prado, M. Cammarota, I. Izquierdo, R.R. Brentani, Physiology of the prion protein, Physiological reviews 88(2) (2008) 673-728.

[9] D.R. Brown, K. Qin, J.W. Herms, A. Madlung, J. Manson, R. Strome, P.E. Fraser, T. Kruck, A. von Bohlen, W. Schulz-Schaeffer, A. Giese, D. Westaway, H. Kretzschmar, The cellular prion protein binds copper in vivo, Nature 390(6661) (1997) 684-7. [10] C. Gabus, S. Auxilien, C. Pechoux, D. Dormont, W. Swietnicki, M. Morillas, W. Surewicz, P. Nandi, J.L. Darlix, The prion protein has DNA strand transfer properties similar to retroviral nucleocapsid protein, Journal of molecular biology 307(4) (2001) 1011-21.

[11] X. Wang, F. Wang, L. Arterburn, R. Wollmann, J. Ma, The interaction between cytoplasmic prion protein and the hydrophobic lipid core of membrane correlates with neurotoxicity, The Journal of biological chemistry 281(19) (2006) 13559-65. [12] B. Caughey, K. Brown, G.J. Raymond, G.E. Katzenstein, W. Thresher, Binding of the protease-sensitive form of PrP (prion protein) to sulfated glycosaminoglycan and congo red [corrected], Journal of virology 68(4) (1994) 2135-41. [13] A. Sailer, H. Bueler, M. Fischer, A. Aguzzi, C. Weissmann, No propagation of prions in mice devoid of PrP, Cell 77(7) (1994) 967-8.

[14] P.M. Lledo, P. Tremblay, S.J. DeArmond, S.B. Prusiner, R.A. Nicoll, Mice deficient for prion protein exhibit normal neuronal excitability and synaptic transmission in the hippocampus, Proc Natl Acad Sci U S A 93(6) (1996) 2403-7.

[15] M. Rogers, A. Taraboulos, M. Scott, D. Groth, S.B. Prusiner, Intracellular accumulation of the cellular prion protein after mutagenesis of its Asn-linked glycosylation sites, Glycobiology 1(1) (1990) 101-9.

[16] S. Lehmann, D.A. Harris, Blockade of glycosylation promotes acquisition of scrapie-like properties by the prion protein in cultured cells, The Journal of biological chemistry 272(34) (1997) 21479-87. 

Mutation, Not the Loss of the First Glycosylation Site, Alters the Physical Properties of the Prion Protein, Journal of Alzheimer's disease : JAD 2(1) (2000) 27-35. [18] S.I. Zaidi, S.L. Richardson, S. Capellari, L. Song, M.A. Smith, B. Ghetti, M.S. Sy, P. Gambetti, R.B. Petersen, Characterization of the F198S prion protein mutation: enhanced glycosylation and defective refolding, Journal of Alzheimer's disease : JAD 7(2) (2005) 159-71; discussion 173-80.

[19] F.K. Wiseman, E. Cancellotti, P. Piccardo, K. Iremonger, A. Boyle, D. Brown, J.W. Ironside, J.C. Manson, A.B. Diack, The glycosylation status of PrPC is a key factor in determining transmissible spongiform encephalopathy transmission between species, Journal of virology 89(9) (2015) 4738-47.

[20] E. Cancellotti, S.P. Mahal, R. Somerville, A. Diack, D. Brown, P. Piccardo, C. Weissmann, J.C. Manson, Post-translational changes to PrP alter transmissible spongiform encephalopathy strain properties, The EMBO journal 32(5) (2013) 75669.

[21] N.L. Tuzi, E. Cancellotti, H. Baybutt, L. Blackford, B. Bradford, C. Plinston, A. Coghill, P. Hart, P. Piccardo, R.M. Barron, J.C. Manson, Host PrP glycosylation: a major factor determining the outcome of prion infection, PLoS biology 6(4) (2008) e100. [22] S.A. Priola, V.A. Lawson, Glycosylation influences cross-species formation of protease-resistant prion protein, The EMBO journal 20(23) (2001) 6692-9. [23] S. Lehmann, D.A. Harris, A mutant prion protein displays an aberrant membrane association when expressed in cultured cells, The Journal of biological chemistry 270(41) (1995) 24589-97. [24] C. Campbell, P. Stanley, The Chinese hamster ovary glycosylation mutants LEC11 and LEC12 express two novel GDP-fucose:N-acetylglucosaminide 3-alpha-Lfucosyltransferase enzymes, The Journal of biological chemistry 259(18) (1984) 11208-14.

[25] G. Zanusso, D. Liu, S. Ferrari, I. Hegyi, X. Yin, A. Aguzzi, S. Hornemann, S. Liemann, R. Glockshuber, J.C. Manson, P. Brown, R.B. Petersen, P. Gambetti, M.S. Sy, Prion protein expression in different species: analysis with a panel of new mAbs, Proceedings of the National Academy of Sciences of the United States of America 95(15) (1998) 8812-6.

[26] L. Yang, Y. Zhang, L. Hu, Y. Zhu, M.S. Sy, C. Li, A panel of monoclonal antibodies against the prion protein proves that there is no prion protein in human pancreatic ductal epithelial cells, Virologica Sinica 29(4) (2014) 228-36.

[27] T. Liu, R. Li, T. Pan, D. Liu, R.B. Petersen, B.S. Wong, P. Gambetti, M.S. Sy, Intercellular transfer of the cellular prion protein, The Journal of biological chemistry 277(49) (2002) 47671-8.

[28] C. Li, S. Yu, F. Nakamura, S. Yin, J. Xu, A.A. Petrolla, N. Singh, A. Tartakoff, D.W. Abbott, W. Xin, M.S. Sy, Binding of pro-prion to filamin A disrupts cytoskeleton and correlates with poor prognosis in pancreatic cancer, The Journal of clinical investigation 119(9) (2009) 2725-36.

[29] C. Li, S. Yu, F. Nakamura, O.T. Pentikainen, N. Singh, S. Yin, W. Xin, M.S. Sy, Proprion binds filamin A, facilitating its interaction with integrin beta1, and contributes to melanomagenesis, The Journal of biological chemistry 285(39) (2010) 30328-39. 
[30] N. Naslavsky, R. Stein, A. Yanai, G. Friedlander, A. Taraboulos, Characterization of detergent-insoluble complexes containing the cellular prion protein and its scrapie isoform, The Journal of biological chemistry 272(10) (1997) 6324-31. [31] K. Simons, R. Ehehalt, Cholesterol, lipid rafts, and disease, The Journal of clinical investigation 110(5) (2002) 597-603.

[32] P.W. Janes, S.C. Ley, A.I. Magee, Aggregation of lipid rafts accompanies signaling via the T cell antigen receptor, The Journal of cell biology 147(2) (1999) 447-61. [33] L.W. Ruddock, H.M. Webb, S.P. Ruston, C. Cheesman, R.B. Freedman, T.R. Hirst, A pH-dependent conformational change in the B-subunit pentamer of Escherichia coli heat-labile enterotoxin: structural basis and possible functional role for a conserved feature of the AB5 toxin family, Biochemistry 35(50) (1996) 16069-76. [34] E.A. Merritt, T.K. Sixma, K.H. Kalk, B.A. van Zanten, W.G. Hol, Galactose-binding site in Escherichia coli heat-labile enterotoxin (LT) and cholera toxin (CT), Molecular microbiology 13(4) (1994) 745-53.

[35] M. Klagsbrun, Mediators of angiogenesis: the biological significance of basic fibroblast growth factor (bFGF)-heparin and heparan sulfate interactions, Semin Cancer Biol 3(2) (1992) 81-7.

[36] J. Folkman, Y. Shing, Control of angiogenesis by heparin and other sulfated polysaccharides, Advances in experimental medicine and biology 313 (1992) 35564.

[37] C.C. Rider, Heparin/heparan sulphate binding in the TGF-beta cytokine superfamily, Biochemical Society transactions 34(Pt 3) (2006) 458-60.

[38] T. Pan, B.S. Wong, T. Liu, R. Li, R.B. Petersen, M.S. Sy, Cell-surface prion protein interacts with glycosaminoglycans, The Biochemical journal 368(Pt 1) (2002) 81-90. [39] S. Yin, N. Pham, S. Yu, C. Li, P. Wong, B. Chang, S.C. Kang, E. Biasini, P. Tien, D.A. Harris, M.S. Sy, Human prion proteins with pathogenic mutations share common conformational changes resulting in enhanced binding to glycosaminoglycans, Proceedings of the National Academy of Sciences of the United States of America 104(18) (2007) 7546-51.

[40] L.C. Cantley, The phosphoinositide 3-kinase pathway, Science 296(5573) (2002) 1655-7.

[41] B.A. Hemmings, D.F. Restuccia, PI3K-PKB/Akt pathway, Cold Spring Harbor perspectives in biology 4(9) (2012) a011189.

[42] R.C. Delos Santos, C. Garay, C.N. Antonescu, Charming neighborhoods on the cell surface: plasma membrane microdomains regulate receptor tyrosine kinase signaling, Cellular signalling 27(10) (2015) 1963-76.

[43] U.M. Lim, M.G. Yap, Y.P. Lim, L.T. Goh, S.K. Ng, Identification of autocrine growth factors secreted by $\mathrm{CHO}$ cells for applications in single-cell cloning media, Journal of proteome research 12(7) (2013) 3496-510.

[44] J.D. Esko, T.E. Stewart, W.H. Taylor, Animal cell mutants defective in glycosaminoglycan biosynthesis, Proc Natl Acad Sci U S A 82(10) (1985) 3197-201. [45] K. Simons, D. Toomre, Lipid rafts and signal transduction, Nature reviews. Molecular cell biology 1(1) (2000) 31-9.

[46] X. Sun, Y. Fu, M. Gu, L. Zhang, D. Li, H. Li, S. Chien, J.Y. Shyy, Y. Zhu, Activation of integrin alpha5 mediated by flow requires its translocation to membrane lipid rafts in vascular endothelial cells, Proc Natl Acad Sci U S A 113(3) (2016) 769-74. 
[47] P. Sharma, R. Varma, R.C. Sarasij, Ira, K. Gousset, G. Krishnamoorthy, M. Rao, S. Mayor, Nanoscale organization of multiple GPI-anchored proteins in living cell membranes, Cell 116(4) (2004) 577-89.

[48] T. Friedrichson, T.V. Kurzchalia, Microdomains of GPI-anchored proteins in living cells revealed by crosslinking, Nature 394(6695) (1998) 802-5.

[49] G.S. Baron, K. Wehrly, D.W. Dorward, B. Chesebro, B. Caughey, Conversion of raft associated prion protein to the protease-resistant state requires insertion of PrP-res (PrP(Sc)) into contiguous membranes, The EMBO journal 21(5) (2002) 1031-40.

[50] A. Rouvinski, S. Karniely, M. Kounin, S. Moussa, M.D. Goldberg, G. Warburg, R. Lyakhovetsky, D. Papy-Garcia, J. Kutzsche, C. Korth, G.A. Carlson, S.F. Godsave, P.J. Peters, K. Luhr, K. Kristensson, A. Taraboulos, Live imaging of prions reveals nascent PrPSc in cell-surface, raft-associated amyloid strings and webs, The Journal of cell biology 204(3) (2014) 423-41.

[51] S. Sawamiphak, S. Seidel, C.L. Essmann, G.A. Wilkinson, M.E. Pitulescu, T. Acker, A. Acker-Palmer, Ephrin-B2 regulates VEGFR2 function in developmental and tumour angiogenesis, Nature 465(7297) (2010) 487-91.

[52] T.T. Chen, A. Luque, S. Lee, S.M. Anderson, T. Segura, M.L. Iruela-Arispe, Anchorage of VEGF to the extracellular matrix conveys differential signaling responses to endothelial cells, The Journal of cell biology 188(4) (2010) 595-609. [53] A.X. Goh, C. Li, M.S. Sy, B.S. Wong, Altered prion protein glycosylation in the aging mouse brain, Journal of neurochemistry 100(3) (2007) 841-54.

[54] T. Liu, T. Zwingman, R. Li, T. Pan, B.S. Wong, R.B. Petersen, P. Gambetti, K. Herrup, M.S. Sy, Differential expression of cellular prion protein in mouse brain as detected with multiple anti-PrP monoclonal antibodies, Brain research 896(1-2) (2001) 118-29.

[55] T. Pan, R. Li, B.S. Wong, T. Liu, P. Gambetti, M.S. Sy, Heterogeneity of normal prion protein in two- dimensional immunoblot: presence of various glycosylated and truncated forms, Journal of neurochemistry 81(5) (2002) 1092-101. [56] P. Parchi, A. Giese, S. Capellari, P. Brown, W. Schulz-Schaeffer, O. Windl, I. Zerr, H. Budka, N. Kopp, P. Piccardo, S. Poser, A. Rojiani, N. Streichemberger, J. Julien, C. Vital, B. Ghetti, P. Gambetti, H. Kretzschmar, Classification of sporadic CreutzfeldtJakob disease based on molecular and phenotypic analysis of 300 subjects, Annals of neurology 46(2) (1999) 224-33.

[57] A.F. Hill, S. Joiner, J.D. Wadsworth, K.C. Sidle, J.E. Bell, H. Budka, J.W. Ironside, J. Collinge, Molecular classification of sporadic Creutzfeldt-Jakob disease, Brain : a journal of neurology 126(Pt 6) (2003) 1333-46.

[58] J. Bjorkqvist, S. de Maat, U. Lewandrowski, A. Di Gennaro, C. Oschatz, K. Schonig, M.M. Nothen, C. Drouet, H. Braley, M.W. Nolte, A. Sickmann, C. Panousis, C. Maas, T. Renne, Defective glycosylation of coagulation factor XII underlies hereditary angioedema type III, The Journal of clinical investigation 125(8) (2015) 3132-46. [59] J. Jaeken, Congenital disorders of glycosylation, Handbook of clinical neurology 113 (2013) 1737-43.

[60] H.H. Freeze, Update and perspectives on congenital disorders of glycosylation, Glycobiology 11(12) (2001) 129r-143r. 
[61] S.R. Stowell, T. Ju, R.D. Cummings, Protein glycosylation in cancer, Annual review of pathology 10 (2015) 473-510. 


\section{Figure Captions}

Fig. 1. Expressing of WT, N181A, N197A and DM PrP in CHO cells. (A) The drawing of PrP shows the locations of the two $\mathrm{N}$-linked glycosylation sites, and the locations of the epitopes recognized by the panel of anti-PrP Mabs $4 \mathrm{H} 2$ and 7A12 used in this study. (B) Flow cytometry analysis with different anti-PrP Mabs reveals similar cell surface PrP expression. Using different anti-PrP Mabs, 4H2 and 7A12, all four cell lines appear to have comparable levels of cell surface PrP. BG: background, empty vector transfected $\mathrm{CHO}$ cells stained with PrP specific Mabs as indicated. (C) Live cells staining with Mab $4 \mathrm{H} 2$ shows similar amount of cell surface PrP expression. Cells were stained with anti-PrP Mab 4H2 (red) at $4^{\circ} \mathrm{C}$. The nuclei were counter stained with DAPI as described. Scale bars: $10 \mu \mathrm{m}$. (D) PrP glycosylation mutants are expressed in $\mathrm{CHO}$ cells at similar level. Immunoblotting of cell lysates from the parental $\mathrm{CHO}$ cells; $\mathrm{CHO}$ cells with wild type PrP (WT); CHO cells with PrP-N181A (N181A); CHO cells with N197A (N197A) or $\mathrm{CHO}$ cells with the double mutant (DM) lacking both glycosylation sites with anti-PrP Mab 4H2. WT PrP contains three PrP isoforms: diglycosylated (DG), mono-glycosylated (MG) and unglycosylated (UG) PrP. While the two single site mutants have MG and UG PrP. The double mutant (DM) only has UG PrP. (E) Immunoblotting of cell lysates from various cell lines after treatment with endoglycosidase $F$ (PNGase F) to remove the glycans with Mab 4H2. PNGase $F$ treated N181A and DM PrP proteins migrated slightly faster than PNGase $F$ treated N197A and WT PrP.

Fig. 2. More glycan-deficient PrP are partitioned in lipid rafts. (A) Cell lysates were prepared from cells expressing either WT or DM PrP and then fractionated as described. The collected fractions were then immunoblotted with either an anti-flotillin-1 Mab (FLOT 1) or an anti-PrP Mab 4H2 (PrP). While the levels of flotillin-1 were comparable between cells bearing WT PrP and DM PrP in the lipid raft associated fractions (Fractions 3-5, panels 1 and 3), the amount of $\operatorname{PrP}$ in these fractions (Fractions 3-5, comparing panels 2 and 4 ) were greatly increased 
in the lysate from DM cells than from WT Cells. (B) The summary and densitometry quantification of 6 different fractionation experiments showing that the amounts of glycan-deficient PrP in the lipid raft fractions (Fractions 3-5) in DM cells were significantly higher than in the corresponding fractions from WT cells. (C) Confocal images showing co-localization of DM PrP (red) and GM1 as revealed by staining with cholera toxin (green) in DM cells (arrows point to the co-location of PrP and GM1). Scale bars: $10 \mu \mathrm{m}$. (D) Pearson's correlation showed significantly more co-location of DM PrP and GM1 than co-location of WT PrP and GM1. The results represent 30 cells randomly collected from 11 images.

Fig. 3. Cells expressing glycan-deficient PrP show activated PI3K-Akt. (A) Cells lysates were prepared from the indicated cell lines cultured in serum free medium and then immunoblotted with antibodies against p-Akt (S473), Akt, pSAPK/JNK (Thr183/Tyr185) or SAPK/JNK. All cells bearing glycan-deficient PrP have higher levels of p-Akt (panel 1) but not Akt (panel 2), p-SAPK/JNK (Thr183/Tyr185) (panel 3) or SAPK/JNK (panel 4). This enhanced p-Akt is absent in DM- $\triangle$ KKRPK cells (panel 1, last lane). Activation of $p$-Akt is inhibited by PI3K inhibitor LY294002 (panels 7 and 8), but not by DMSO (panels 5 and 6). (B) Inhibitors of VEGFR prevent increase in p-Akt in cells bearing glycan-deficient $\operatorname{PrP}$ (panels 1 and 5). All cells were cultured in serum free medium and incubated with various chemical inhibitors as described in Material and Methods. Cell lysates were prepared at the end of culture and immunoblotted with either anti-pAkt (S473) or anti-Akt. Only inhibitors of VEGFR (panel 1) or VEGFR2 (panel 5) but not VEGFR1 (panel 3) or VEGFR3 (panel 7) diminish the levels of p-Akt in cells bearing glycan-deficient PrP. (C) The other tested non-VEGFR2 inhibitors (AG490, BGJ398, BMS754807, Crizotinib, Mubritinib, and RGD) at the indicated concentrations did not attenuate p-Akt signaling in N181A, N197A, and DM PrP expressing $\mathrm{CHO}$ cells. The experiments were repeated three times with similar results. 
Fig. 4. Glycan-deficient PrP binds VEGFR2 via its N-terminal KKRPK domain. (A) Confocal images showed the co-location of glycan-deficient PrP and VEGFR2 in DM cells. WT and DM cells were stained with anti-PrP Mab 4H2 (red) or anti-VEGFR2 antibody (green) and viewed in a confocal microscopy. More colocation of PrP and VEGFR2 were seen in DM cells compared to WT cells (arrows point to the co-location of PrP and VEFGR2, comparing to right columns). Scale bars: $10 \mu \mathrm{m}$. (B) PrP co-immunoprecipitated with VEGFR2 in glycandeficient cells but not in cells with WT PrP. The amount of PrP coimmunoprecipitated with VEGFR2 is greatly reduced in DM- $\triangle$ KKRPK cells (last lane of top panel). Total VEGFR2 pulled down by the antibody were shown (second row of top panel) to indicate similar amount of loading. IgG heavy chain used for co-IP is revealed to show similar amount of antibody used for co-IP (third row of top panel). P-VEGFR2 was activated in glycan-deficient PrP cells and the activation required KKRPK (last lane of bottom panel). Quantification of amount PrP was pulled down by VEGFR2 based on densitometry (top right panel) and quantification of $\mathrm{p}$-VEGFR2 from $\mathrm{CHO}$ cells expressing different forms of PrP based on densitometry (bottom right panel). The experiments were repeated three times with similar results. (C) Knockdown VEGFR2 in DM PrP CHO cells reduces p-Akt level. Immunoblotting with anti-VEGFR2 specific polyclonal antibody confirmed the reduction of VEGFR2 in siRNA knocking down DM PrP $\mathrm{CHO}$ cells using four different siRNA sequences (1 to 4) (panel 1). Activation of Akt is reduced when VEGFR2 is down regulated (panel 2). Quantification of VEGFR2 and p-Akt levels in various VEGFR2 down regulated cells based on densitometry using image $\mathrm{J}$ (Bottom panels). The experiments were repeated three times with similar results.

Fig. 5. The GAG binds glycan-deficient PrP to stimulate signaling. (A) Confocal images showed more co-location of glycan-deficient PrP and heparin in DM cells (right panel) than in WT cells (left panel). WT and DM cells were stained with anti-PrP Mab bio-4H2 (green) or anti-heparin Mab (red) and viewed in a confocal microscopy (arrows point to the co-location of PrP and heparin). Scale 
bars: $10 \mu \mathrm{m}$. (B) Treatment of glycan-deficient PrP cells cultured in FBS free medium with heparinase decreases Akt phosphorylation compare to control vehicle treated cells. (C) Quantification of results in (B) from four different experiments based on densitometry revealed a significant reduction (25-30\%) of p-Akt after heparinase treatment. (D) Expressing of DM PrP in GAG deficient pgsA-745 cells did not elevate p-Akt signaling compare to WT PrP. Expression of comparable levels of WT and DM PrP on the cell surface of transfected pgsA-745 cells based on $4 \mathrm{H} 2$ staining (left panel); BG: background, empty vector transfected pgsA-745 cells stained with $4 \mathrm{H} 2$. Immunoblotting with PrP specific Mab 4H2 confirmed the expression of WT and DM PrP in pgsA-745 cells (right panel). (E) Expression of DM PrP in pgsA-745 cells did not increase the level of p-Akt (right two lanes) whereas DM PrP expressed in GAG sufficient $\mathrm{CHO}$ cells did activate Akt compare to WT PrP (left two panels). The experiments were repeated three times with similar results.

\section{Fig. 6. GPI anchor is essential for glycan-deficient PrP to engage in PI3K-} Akt signaling. (A) Drawings of various PrP-CD4 transmembrane and cytoplasmic domain chimeric proteins. (B) Flow cytometry analysis revealed that the PrP-CD4 chimeric proteins (WT-CD4, DM-CD4) were detectable on the cell surface, and had similar expression level as GPI anchored PrP (WT, DM) as stained with anti-PrP Mab 4H2. BG: background, empty vector transfected $\mathrm{CHO}$ cells stained with $4 \mathrm{H} 2$. (C) Immunoblotting with anti-PrP Mab $4 \mathrm{H} 2$ revealed the presence of the chimeric proteins (WT-CD4, N181A-CD4, N197A-CD4, DM-CD4) in various cell lines. The Mol. Mass of the chimeric protein is about $10 \mathrm{kDa}$ larger than the WT PrP due to the inclusion of the CD4 transmembrane and cytoplasmic domain. (D) Confocal images showing less PrP-CD4 chimeric proteins (WT-CD4, N181A-CD4, DM-CD4) co-localize with GM1 if the GPI anchor was replaced with CD4 transmembrane domain. WT-CD4, N181A-CD4, and DM-CD4 cells were stained with anti-PrP Mab 4H2 (green) or cholera toxin (red) to label GM1, and viewed in a confocal microscopy (arrows point to the colocation of PrP and GM1). Scale bars: $10 \mu \mathrm{m}$. (E) The amount of DM-CD4 
chimeric protein found in lipid rafts (fractions 3-5, top panel) was greatly reduced compared with GPI anchored DM PrP (bottom panel). Cell lysates were fractionated and each fraction was immunoblotted with anti-PrP Mab 4H2. (F) Being GPI-anchored was important in enhancing $p$-Akt. The levels of $p$-Akt were reduced in cells bearing glycan-deficient PrP-CD4 chimeric proteins (labelled as CD4) compared with cells with corresponding GPI anchored PrP (labelled as GPI). (G) Quantification of results in (F) based on densitometry showed a 25-50\% reduction of p-Akt level in PrP-CD4 chimeric protein expressing cells than in GPI anchored PrP expressing cells. The experiments were repeated twice with similar results.

Fig. 7. MG and UG PrP cells tend to spread and migrate faster than WT PrP cells. (A) Significantly faster spreading of $M G$ and UG PrP cells on heparin coated glass bottom petri dish $(n=3, p<0.05)$ comparing WT to MG and UG PrP expressing cells). (B) N181A and UG PrP cells migrated significantly faster than DG PrP and DM- $\triangle K K R P K$ PrP cells $(n=5, p<0.05)$. (C) A model proposed to explain UG PrP when localizing in lipid raft could bind GAG and activate VEGFR2, thus activating PI3K-Akt pathway. N-linked glycans prevent the binding between PrP and VEGFR2 or VEGFR2 and GAG (left panel). GAG binding domain at the $\mathrm{N}$-terminus of $\operatorname{PrP}$ (orange colored) is required for PrP, GAG, and VEGFR2 signaling. Without this domain PrP can not interact with GAG (middle panel). Glycan-deficient PrP forms complex with GAG and VEGFR2 thus activating PI3K-Akt signaling pathway (right panel). 
1

2

3

\section{Glycan-deficient PrP stimulates VEGFR2 signaling via glycosaminoglycans}

Zhenxing Gao ${ }^{\mathrm{a}, \mathrm{d}}$, Huixia Zhang ${ }^{\mathrm{a}}$, Fei Hu ${ }^{\mathrm{b}}$, Liheng Yang ${ }^{\mathrm{a}, \mathrm{d}}$, Xiaowen Yang ${ }^{\mathrm{c}}$, Ying Zhu ${ }^{d}$, Man-Sun Sy ${ }^{\mathrm{e}}$, Chaoyang $\mathrm{Li}^{\mathrm{f}},{ }^{*}$

aUniversity of Chinese Academy of Sciences, Center for Molecular Virology, Wuhan Institute of Virology, Chinese Academy of Sciences, 44 Xiao Hong Shan Zhong Qu, Wuhan, 430071, China;

'Wuhan Brain Hospital, No.5 Huiji Road, Jiang'an district, Wuhan, 430010, China; 'Department of the First Abdominal Surgery, Jiangxi Tumor Hospital, Nanchang, 330029, China;

${ }^{d}$ Department of Virology, School of Life Sciences, Wuhan University, State Key Laboratory of Virology, Wuhan, 430072, China;

eDepartment of Pathology, School of Medicine, Case Western Reserve University, 2106 Cornell Road, Cleveland, OH, 44106, USA;

${ }^{f}$ Center for Molecular Virology, Wuhan Institute of Virology, Chinese Academy of Sciences, State Key laboratory of Virology; Wuhan Brain Hospital, 44 Xiao Hong Shan Zhong Qu, Wuhan, 430071, China.

"Corresponding author at: 44 Xiao Hong Shan Zhong Qu, Wuhan, 430071, China. E-mail address: cyli@wh.iov.cn (Chaoyang Li) 
N-linked glycosylation plays an important role in protein function. Whether the two N-linked glycans are important in prion, $\mathrm{PrP}$, biology is-unsettled unresolved. In Chinese hamster ovary $(\mathrm{CHO})$ cells, the two glycans are clearly not important in the cell surface expression of transfected human PrP. Compared to fullyglycosylated PrP, glycan-deficient PrP preferentially partitions more into lipid raft. than fully glycosylated PrP. CHO cells bearing glycan-deficient PrP forms-in $\mathrm{CHO}$ cells glycan-deficient PrP also interacts complex-with glycosaminoglycan (GAG) and vascular endothelial growth factor receptor 2 (VEGFR2), resulting in VEGFR2 activation and enhanced Akt phosphorylation. Accordingly, $\mathrm{CHO}$ cells expressing glycan-deficient PrP lacking the GAG binding motif or cells treated with heparinase to remove GAG have-show diminished Akt signaling. Being in lipid raft is critical, Chimeric chimeric glycan-deficient PrP with CD4 transmembrane and cytoplasmic domains is absent in lipid raft and does not activate Akt signaling. $\mathrm{CHO}$ cells bearing glycan-deficient PrP also exhibit enhanced cellular adhesion and migration. Therefore, $\mathrm{N}$-linked glycans on PrP provide a negative function, reducing VEGFR2 signaling. Based on these findings, We we propose a model based on the results in which under glycosylated glycan-deficient PrP, GAG, and VEGFR2 interact, activating VEGFR2 and resulting in changes in cellular behavior.form a protein complex to stimulate VEGFR2 signaling. We posit that defect in glycosylation of PrP may contribute to neurodegeneration and cancer.

Key words: PrP; GAG; N-linked glycosylation; lipid raft; VEGFR2 


\section{Introduction}

One of the most common protein post-translational modifications-of proteins, is $\mathrm{N}$-linked glycosylation. $\mathrm{N}$-linked glycosylation is important in proper protein folding, transit to the cell surface and secretion, in a protein, as well as cell context dependent manner-[1-4]. The normal human cellular prion protein, PrP, is a widely expressed, highly conserved, glycosylphosphatidylinositol (GPI)anchored cell surface glycoprotein [5-7]. The two N-linked glycosylation sites of on human PrP are located at the C-terminus at residues 181 and 197. A plethora of more than 40 proteins have been reported to bind PrP [8]. In addition, PrP also | binds divalent cations, such as copper and zinc, lipids, nucleic acids and GAGs [9-12]. However, other than being essential for the pathogenesis of prion diseases, the normal functions of PrP remain obscure; Prnp ${ }^{-/}$mouse is normal without apparent phenotype $[13,14]$. Whether the two glycans are important in | PrP biology is debated. In some cell models, glycan--deficient PrP is retained in the cytosol, unable to reach the cell surface $[15,16]$. On the contrary, other studies find them to be dispensable for cell surface expression [17, 18]. Even though the two $\mathrm{N}$-linked glycans are not essential for the pathogenesis of prion diseases generation of infectious prion, they do contribute to disease phenotypes as well as strain specificity of some infectious prion [19-22]. However, the underlying mechanisms by which $\mathrm{N}$-linked glycans modulate disease phenotype or strain specificity are not known.tit is not clear why the $\mathrm{N}$-linked-glycans influence the disease phenotype or strain specificity since how $\mathrm{N}$-linked glycans affect the physiological functions of PrP is unknown.

Because of these ambiguities, we investigated whether the two $\mathrm{N}$-linked glycans were important in PrP biology using $\mathrm{CHO}$ cell, which lacked detectable endogenous hamster PrP [23]. We transfected a wild type (WT) human PrP; a single glycan site mutant (SM) PrP, in which one of the glycosylation sites, asparagine (N) 181, was altered to an alanine (A) (N181A); another SM PrP, in which the other site, N197, was mutated to an A (N197A); a double mutant (DM) PrP, in which both sites were replaced with $\mathrm{A}$ individually into $\mathrm{CHO}$ cells. These 
mutated PrP are collectively referred to as glycan-deficient PrP. We find that all glycan-deficient PrP are expressed on the cell surface in levels comparable to WT PrP. However, glycan-deficient PrP appears to partitions more in lipid raft than wild-type PrP-with $\mathrm{N}$-linked glycans. Furthermore, $\mathrm{CHO}$ cells expressing glycan-deficient PrP forms complex with VEGFR2 and GAG thus stimulating resulting in the activation of VEGFR2 and the mediated PI3K-Akt signaling pathway, $\bar{j}_{\text {. }}$ and finally resulting faster cell spreading and motility than $\mathrm{CHO}_{\mathrm{H}}$ cells expressing di-glycosylated PrP. Our results showed that $\mathrm{N}$-linked glycans - These biochemical alterations also resulted in changes in cellular behavior; compared to cells with wild type PrP, cells with glycan-deficient PrP are more adhesive and more mobile. Collectively, these results suggest that in $\mathrm{CHO}$ cells, one of the functions of $\mathrm{N}$-linked glycans on $\operatorname{PrP}$ is to negatively regulate $\operatorname{PrP}$ functions.

\section{Materials and methods}

\subsection{Cell lines}

Chinese hamster ovary $(\mathrm{CHO})$ cell line was kindly provided by Dr. Pamela Stanley of Albert Einstein College of Medicine, New York City, NY [24]. The cells | were cultured with Minimum Essential Medium Alpha-Alpha (11900024, Gibco), 1\% antibiotic Penicillin-Streptomycin solution (PS) (03-031-1, Biological Industries) plus $10 \%$ fetal bovine serum (FBS) (04-001-1, Biological Industries). The pgsA745 cell line was purchased from ATCC (CRL-2242), the cells were cultured with F-12K Medium (30-2004, ATCC) plus 10\% FBS and 1\% PS as suggested by the vendor. All cells were cultured in a $37^{\circ} \mathrm{C}, 5 \% \mathrm{CO}_{2}, 95 \%$ humidity incubator (Series 8000 WJ, Thermo Scientific). All studies on signal transduction were earried out in culture medium without FBS.

\subsection{Antibodies and other reagents}


Anti-PrP Mabs 4H2 and 7A12 were produced, purified, characterized and (Ser473) (4060), Akt (4691), p-SAPK/JNK (4668), SAPK/JNK (9252), HRP linked goat anti-mouse IgG (7076), HRP linked goat anti-rabbit IgG (7074), and LY294002 (9901) were purchased from Cell Signaling Technology. Antibodies against VEGFR2 (Flk-1) (sc-505), p-VEGFR2 (p-Flk-1) (sc-101820), flotillin-1 (sc25506) and Protein A/G PLUS-Agarose (sc-2003) were purchased from Santa Cruz Biotechnology. Heparin antibody (MAB2040) was purchased from Merck Millipore. Receptor tyrosine kinase (RTK) inhibitors AG490 (S1143), Axitinib (S1005), BGJ398 (S2183), BMS754807 (S1124), Crizotinib (S1068), Ki8751 (S1363), Mubritinib (S2216), RGD peptides (S8008), SAR131675 (S2842), ZM306416 (S2897) were purchased from Selleck Chemicals (Texas, USA). Heparinase I and III (H3917) were purchased from Sigma. Proteinase inhibitor cocktail (11697498001) and 4', 6-diamidino-2-phenylindole (DAPI) (10236276001) were purchased from Roche. Alexa fluor-Fluor 555 conjugated goat anti-rabbit IgG (A-21429), alexa-Alexa fluor-Fluor 555 conjugated goat anti-mouse IgG (A21424), alexa Alexa fluor Fluor 647 conjugated goat anti-mouse IgG (A-21235), alexa-Alexa fluor-Fluor 647 conjugated streptavidin (S-21374), and Lipofectamine 2000 transfection reagent (11668-019) were purchased from Invitrogen. EZ-link Sulfo-NHS-Biotinylation kit (21425) was purchased from Thermo scientific. All the other chemicals were purchased from Amresco (OH, USA).

\subsection{Construction of different human PrP mutants}

Cloning vector pHAGE-CMV-MCS-IZsGreen and the packaging plasmids psPAX2, pMD2.G were kindly provided by Prof. Zan Huang (Wuhan University). Wild type human PRNP (hPrP) DNA was created as described [27]. Constructions of hPrP-N181A, hPrP-N197A, hPrP-N181A-N197A (double mutation, hPrP-DM), and hPrP-DM- $\triangle$ KKRPK were made by Site-directed Gene Mutagenesis Kit (D0206, Beyotime, Shanghai, China). For the constructions of different PrPs-CD4 chimeric proteins, human CD4 transmembrane domain and 
cytosol tail was amplified with the indicated primer pairs (Table S1) containing restriction enzyme Bsp119 I site before the GPI-anchor signal sequence in the forward primer, and restriction enzyme BamH I site in the reverse primer. The site of Bsp119 I was deleted after CD4 transmembrane and cytosol domain was inserted into the PrP expressing constructs. All the constructs were sequence confirmed.

\subsection{Expression of human PrP in $\mathrm{CHO}$ cells}

Wild type and mutant PrP were inserted in the pHAGE-CMV-MCS-IZsGreen vector and transfected into $293 \mathrm{~T}$ cells as described [28, 29]. Lentiviral particles were collected by centrifuging at $700 \times g$ for 10 minutes, and filtered with $0.45 \mathrm{~nm}$ filter. $\mathrm{CHO}$ or pgsA-745 cells were then infected with the virions for 6 hours. $\operatorname{PrP}$ expressing cells were sorted out expression was confirmed by-flow cytometry based on cell surface PrP staining to establish stable cell lines which were then used for this study immunofluorescent staining followed by flow cytometric analysis.

\subsection{Co-immunoprecipitation (Co-IP)}

PrP expressing cells were seeded 14 hours-in culture medium at $37^{\circ} \mathrm{C}, 5 \%$ $\mathrm{CO}_{2}, 95 \%$ humidity for 14 hours. The cells were cultured for an additional 24 hours in medium without FBS. After that Gells-cells were then-lysed in cell lysis buffer (20 mM Tris-HCl (pH 7.5), $150 \mathrm{mM} \mathrm{NaCl}, 1 \mathrm{mM} \mathrm{Na}{ }_{2}$ EDTA, 1 mM EGTA, $2.5 \mathrm{mM}$ sodium pyrophosphate, $1 \mathrm{mM}$ b-glycerophosphate, $1 \mathrm{mM} \mathrm{Na}_{3} \mathrm{VO}_{4}, 1 \%$ Triton, $1 \mathrm{mM}$ PMSF and 1_x proteinase inhibitor cocktail) and protein concentration was quantified using a Bio-Rad Protein Assay (500-0002, Bio-Rad). Before co-IP, cell lysate were pre-cleared with rabbit $\lg G$ and protein $A / G$ agarose beads for 1 hour at $4^{\circ} \mathrm{C}$. Pre-cleared lysate were incubated with $2 \mu \mathrm{g}$ of indicated antibodies at $4^{\circ} \mathrm{C}$ for 14 hours. The protein $A / G$ agarose beads were 
then added for an additional 3 hours and incubated at $4^{\circ} \mathrm{C}$. After washing the reaction for 6 times with cell lysis buffer, the beads were collected by centrifuging at $1000 \times g$ for 1 minute. $30 \mu \mathrm{l} 1.3 \times$ reducing sample loading buffer $(10 \%$ sucrose (W/V), 5\% 2-mercaptoethanol (V/V), 2\% SDS (W/V), $0.0625 \mathrm{M}$ Tris- $\mathrm{HCl}$ $\mathrm{pH}$ 6.8, $0.0004 \%$ bromophenol blue $(\mathrm{W} / \mathrm{V}))$ ) were then added to the beads. Proteins co-purified with VEGFR2 were subjected to immunoblotting.

\subsection{Immunoblotting}

Cells were growing under specified conditions. Cell lysate were made according to Li-Cultured cells were harvested, lysed, and cell lysate prepared as described by us [28]. The concentration of proteins was measured by Bio-Rad Protein Assay (500-0002, Bio-Rad). Proteins were quantified-Comparable levels of proteins were loaded and separated on 10\% SDS-PAGE gel. After-get electrophoresis, proteins were transferred to a nitrocellulose membrane (HATF00010, Merck Millipore) and blocked in 3\% BSA in TBST (137 mM NaCl, $20 \mathrm{mM}$ Tris, $0.1 \%$ Tween-20, $\mathrm{pH} 7.6)$ overnight at $4^{\circ} \mathrm{C}$. To detect the proteins on nitrocellulose membrane, the blots were first probed with the primary antibody. Bound primary antibodies were then further probed with a HRP-conjugated secondary antibodiesantibody. The concentration of anti-PrP antibodies $4 \mathrm{H} 2$ and $7 \mathrm{~A} 12$ were was $1 \mu \mathrm{g} / \mathrm{ml}$. All the other primary antibodies were used according to the manufacturer's instruction.

To detect PrP expressing in pgsA-745 cells, PrP expressing cells were sorted out based on surface PrP staining and cultured as suggested by ATCC and PAkt, Akt, actin were probed according to manufacturer's protocol (Cell Signaling Technology).

PNGase $F$ (P0704S, NEB) treatment of PrP was performed according to manufacturer's instruction. Briefly, $20 \mu \mathrm{g}$ proteins per sample were combined with $1 \mu \mathrm{l} 10 \times$ glycoprotein denaturing buffer and deionized water to make a $10 \mu \mathrm{l}$ reaction volume on ice. The sample was then boiled for 10 minutes, and $2 \mu \mathrm{l} 10 \times$ G7 buffer, $2 \mu \mathrm{l}$ 10\% NP40, $5 \mu$ l deionized water and $1 \mu \mathrm{l}$ PNGase F were added 


\subsection{Cell surface biotinylation}

Cell surface biotinylation was performed according to manufacturer's protocol | (21331, Thermo scientific). After protein biotinylation, the biotin conjugated proteins were pulled down with streptavidin beads ( $\mathrm{N}-1000$, Solulink). Proteins were further separated with 10\% SDS-PAGE gel and immunoblotted with $4 \mathrm{H} 2$ accordingly. The amount of unglycosylated, mono-glycosylated, and diglycosylated PrP were quantified based on densitometry using the Image $\mathrm{J}$ software (NIH).

\subsection{Immunofluorescence staining}

CHO cells transfected with expressing WT-PrP, N181A-PrP, N197A-PrP, and or DM-PrP were cultured as described in above. PrP expressing or control cells were seeded in the poly-D-lysine coated glass bottom culture dishes (801002, NEST) 14 hours before experiment.-To detect PrP expression, single cell suspension-cells was-were detected with Mab $4 \mathrm{H} 2(10 \mu \mathrm{g} / \mathrm{ml})$ at $4^{\circ} \mathrm{C}$ for 1 hour. Bound antibodies were detected with alexa-Alexa fluor Fluor 555 conjugated goat anti-mouse antibody $(1 \mu \mathrm{g} / \mathrm{ml})$ for 1 hour at $4{ }^{\circ} \mathrm{C}$.

To-For double labeling of $\operatorname{PrP}$ (GPI anchored and CD4 chimeric PrP) and GM1,* Formatted: Indent: First line: $1 \mathrm{ch}$ the cells were seeded as above. GM1 was labeled with the Vybrant lipid raft labeling kits (V-34404, Molecular Probes) according to the manufacturer's instructions. Briefly, cells were incubated with medium plus alexa-Alexa fluor Fluor 555 conjugated CT-B $(1 \mu \mathrm{g} / \mathrm{ml}) 10$ minutes at $4^{\circ} \mathrm{C} .200$-fold dilution of antiCT-B antibodies were then added to crosslink the CT-B labelled lipid rafts. PrP was detected with Mab $4 \mathrm{H} 2(10 \mu \mathrm{g} / \mathrm{ml})$ as described above. Mouse lgG1 or rabbit IgG tsotype-isotype control were used applied-as negative controls. Nuclei were counter stained with DAPI. Images were taken with A1 MP+ multiphoton confocal 
microscope (model, IMA101065ALS, Nikon) after adding anti-fade mounting media (P0128, Beyotime). Co-localization of PrP and GM1 was counted from 30 cells in 11 randomly selected images. Pearson's correlation was used to show the co-localization according to NIS-Elements AR instruction.

Fo-For double labeling of PrP and VEGFR2, the-cells were cultured as described in above. Rabbit polyclonal antibody specific for VEGFR2 polyclonal antibody $(5 \mu \mathrm{g} / \mathrm{ml})$ and Mab $4 \mathrm{H} 2(10 \mu \mathrm{g} / \mathrm{ml})$ were applied to culture medium at $4^{\circ} \mathrm{C}$ for 1 hour. After extensive washing to remove unbound antibody, Bound bound primary antibodies were probed with alexa Alexa fluor Fluor 555 conjugated goat anti-rabbit $\operatorname{lgG}(1 \mu \mathrm{g} / \mathrm{ml})$ or alexa Alexa fluor-Fluor 647 conjugated goat anti-mouse $\operatorname{lgG}(1 \mu \mathrm{g} / \mathrm{ml})$ for 1 hour at $4^{\circ} \mathrm{C}$. Mouse $\lg \mathrm{G} 1$ or rabbit IgG tsotype-isotype control were usedapplied as negative controls. Images were taken as described in above.

To-For double tabelling labeling of PrP and heparin, anti-heparin Mab (10 $\mu \mathrm{g} / \mathrm{ml}$ ) was applied-added to cultured cells at $4^{\circ} \mathrm{C}$ for 1 hour. Bound antibody was probed with alexa Alexa fluor Fluor 555 conjugated goat anti-mouse IgG (1 $\mu \mathrm{g} / \mathrm{ml}$ ). Mouse lgG1 isotype control was used to block extra goat antibodies. PrP was then detected with bio- $4 \mathrm{H} 2(10 \mu \mathrm{g} / \mathrm{ml})$ for 1 hour at $4^{\circ} \mathrm{C}$. Bound biotin was then probed with alexa Alexa fluor Fluor 647 conjugated streptavidin $(1 \mu \mathrm{g} / \mathrm{ml})$. Images were taken as described in above.

\subsection{Flow cytometry staining of cell surface PrP}

Cells in tissue culture flasks GPI anchored PrP expressing or control cells were treated with 25 mM EDTA (0105, Amresco) diluted in PBS ( $\mathrm{pH} 7.6$ ) for 3 minutes to release the cells. Single cell suspension was centrifuged at $200 \times g$ for 3 minutes at $4^{\circ} \mathrm{C}$. The collected cells were washed twice with ice cold PBS then incubated with Mabs $4 \mathrm{H} 2$ or $7 \mathrm{~A} 12$ at $10 \mu \mathrm{g} / \mathrm{ml}$ diluted in PBS for 30 minutes on ice. Bound antibodies were detected with the APC conjugated goat anti-mouse $\operatorname{lgG}\left(405308\right.$, BioLegend) at $2 \mu \mathrm{g} / \mathrm{ml}$ for an extra 30 minutes at $4{ }^{\circ} \mathrm{C}$. Bound 
secondary antibodies were analyzed with the FACSAria III (model, 648282, BD Biosciences). Mouse IgG1 was applied as a negative control or antibody stained empty vector transfected cells was applied as a negative control.

To detect cell surface PrP expression on pgsA-745 cells, WT and DM-PrP expression plasmids were transfected into pgsA-745 cells the same as into $\mathrm{CHO}$ cells and cultured under specified condition. Cells were then sorted out and treated as those in $\mathrm{CHO}$ cells.

To detect surface chimeric PrP-CD4 expression, $\mathrm{CHO}$ cells transfected with WT-PrP-CD4, DM-PrP-CD4, and SM-PrP-CD4 were cultured as above. Surface PrP was stained with $\mathrm{Mab}-4 \mathrm{H} 2$ exactly the same as $\mathrm{GPI}$ anchored PrP surface staining.

\subsection{RNA interference of hamster VEGFR2}

SiRNAs against $\mathrm{CHO}$-specific for hamster VEGFR2 were listed in Table S2. The sequences were designed by online software siDESIGN Center (GE Dharmacon, CO, USA), and synthesized by GenePharma-company (Shanghai, China). The cells were seeded 14 hours at $37^{\circ} \mathrm{C}, 5 \% \mathrm{CO}_{2}, 95 \%$ humidity, $\mathrm{CHO}$ cells expressing PrP were transfected with siRNAs by lipofectamine 2000 in the absence of FBS for 6 hours. Cells were then cultured in medium with 10\% FBS

for 24 hours before replacing with serum free medium for additional 24 hours for signal transduction assays. Cell lysate were prepared for immunoblotting according to Li-as described by us [28]. Relative expression of level was quantified using Image $\mathrm{J}$ software $(\mathrm{NIH})$.

\subsection{Lipid raft assays}

Lipid raft fractionation was performed as described [28]. Briefly, the cells were cultured in $10 \mathrm{~cm}$ petri dish (310109011, Thermo Fisher) at $37^{\circ} \mathrm{C}, 5 \% \mathrm{CO}_{2}, 95 \%$ humidity and then lysed in Mes-buffered saline (25mM Mes, $150 \mathrm{mM} \mathrm{NaCl}, \mathrm{pH}$ 6.5) containing $1 \%$ Triton X-100 plus -1 mM PMSF and 1_x proteinase inhibitor 
cocktail. A $1 \mathrm{ml} 40 \%$ of lysate was made by adding $0.5 \mathrm{ml}$ lysate with equal volume of $80 \%$ sucrose in Mes-buffered saline. 3 Three $\mathrm{ml} 30 \%$ sucrose in Mesbuffered saline were then loaded on top of the $40 \%$ fraction. Finally, $1 \mathrm{ml} 5 \%$ sucrose in Mes-buffered saline was placed on the top. The samples were centrifuged at $180,000 \times g$ in an SW-55 rotor (Beckman) for 17 hours at $4^{\circ} \mathrm{C}$. Sucrose gradients were collected as $500 \mu \mathrm{l}$ per fractions from the top the bottom. Proteins in each fraction were separated on 10\% SDS-PAGE gels and immunoblotted with indicated antibodies.

\subsection{Signaling transduction assays}

To detect signal transduction alteration due to different PrP expression or heparinase or drug treatment, the cells were first cultured 14 hours in medium supplemented with $10 \%$ FBS. In the case of drug treatment, cells were then cultured in medium without FBS for an additional 24 hours before making cell lysate, or cells were cultured in medium without FBS for 24 hours but drugs at specified concentrations were added in culture medium 2 hours before making cell lysate. In the case of heparinase treatment, cells were cultured in medium without FBS for 24 hours but heparinase at specified concentration was added in culture medium 4 hours before making cell lysate. Cell lysate were made as described in above. Proteins were then separated on 10\% SDS-PAGE gel and transferred on a nitrocellulose membrane. Target molecules were probed with specific antibodies according to manufacturer's instruction.

\subsection{Cell adhesion assays}

Cells were treated with $2.50 .25 \%$ trypsin-EDTA for 30 seconds in incubator and then were shaken vigorously to detach from the culture flask. Digested cells were immediately mixed with culture medium containing $10 \%$ FBS to neutralize trypsin enzymatic activity and then centrifuged at $200 \times g$ for 5 minutes. Single cell suspension was reconstituted with medium. $1 \times 10^{4} \mathrm{PrP}$ expressing cells 
were seeded in heparin coated glass bottom culture dishes for 15 minutes, the non-adhesion cells were aspirated off and adherent cells were fixed at $4 \%$ paraformaldehyde. Adherent cells were counted with microscopy.

\subsection{Cell migration assays}

Cells were cultured in a 6 well plate till $100 \%$ confluency and then the medium was replaced with new medium without FBS. Wound was created with a tip-cut $200 \mu \mathrm{l}$ pipette tip. The wound areas were photographed at 6,12 and 24 hours after wound creation. Image $\mathrm{J}(\mathrm{NIH})$ software was applied to quantify the wound healing areas. Briefly, based on Image $J$, the readings (A) of newly created wound areas as one hundred percent, after the indicated time points post wound infliction, un-wound area readings $(B)$ were quantified, and the healing ratio was calculated as $1-\mathrm{B} / \mathrm{A}$.

\subsection{Statistical analyses}

All of the experiments were repeated at least 3 times and analyzed by student's t-test; quantitative data are expressed as the mean and standard error of the mean. $p<0.05$ was considered statistically significant.

\section{Results}

3.1. The two N-linked glycans on PrP are not essential for the expression of PrP on the cell surface of $\mathrm{CHO}$ cells

The epitopes of the anti-PrP Mabs and the location of the glycosylation sites are shown in Fig. 1A. We use flow cytometry to enrich for sort out-PrP expressing stable-expression cell lines transfected with WT, N181A, N197A, or double mutant (DM) PrP. Cells were stained with anti-PrP Mabs, 4H2 or 7A12 -to show that all cell lines have comparable cell surface PrP level (Fig. 1B). 
| Immunofluorescence staining confirms-and confocal imaging analysis reveal the expression of various PrP isoforms at comparable levels on the cell surface (Fig. 1C). By immunoblotting using Mab 4H2, majority of WT PrP is di-glycosylated (DG), most of the N181A and N197A are mono-glycosylated (MG), and the DM is unglycosylated (UG) (Fig. 1D). After PNGase $F$ treatment, all four proteins migrate as UG PrP (Fig. 1E). Hence, the N-linked glycans are not required for human PrP expression on the cell surface.

\subsection{Glycan-deficient PrP partitions more in lipid raft than di-glycosylated PrP}

Like other GPI-anchored proteins, $\operatorname{PrP}$ is found in lipid rafts [30, 31]. $\underline{\mathrm{N} \text {-linked }}$ glycans are highly negative charged, and thus repulsive [1-4]. Therefore, We-we next investigated whether $\mathrm{N}$-linked glycans influence the partition of PrP in lipid rafts. More DM PrP was found in the lipid raft fractions (fractions 3-5), the amount based on densitometry the amount ranged from 30 to $45 \%(n=6)$ of the total PrP. In contrast, between 10 to $15 \%(n=6)$ of the total WT PrP was found in the lipid raft fractions (Fig. 2A, B). As a consequence, Accordingly, proportionally less percentage of DM PrP was observed in non-lipid raft fractions compared to than WT PrP (Fractions 8-10). We use Flotillinflotillin- $1_{2}$ is-a lipid raft associated protein as a control.; the-The levels of flotillin-1 in the lipid raft were comparable between the PrP-DM and PrP WT cells (Fig. 2A, comparing panels 1 and 3) indicating that the difference is limited to PrP.

Ganglioside, GM1, is a major lipid raft component [32]. Cholera toxin binds GM1, and is used extensively to visualize lipid rafts on the cell surface [33, 34]. Therefore, we use two-color immunofluorescence staining to determine whether more DM PrP is co-localized with GM1 on the cell surface. By immunofluorescence staining we-We found that there were-was more colocations of PrP and GM1 on the surface of PrP-DM cells compared to PrP-WT cells (Fig. 2C). Pearson's correlation between PrP and GM1 is significantly higher for DM PrP and GM1 than for WT PrP and GM1 (Fig. 2D), thus supporting that glycan-deficient PrP localized more in lipid raft than di-glycosylated PrP. 
3.3. Cells bearing glycan-deficientunder glycosylated PrP activate signaling involving VEGFR2 and GAG

Some cell surface receptors, such as VEGFR, bFGFR and TGFBR require GAG for optimal signaling [35-37]. It is also known that PrP can bind cell surface GAG [38] and binding requires the presence of KKRPK at the N-terminus of PrP [39]. PrP has been implicated in many signaling pathways [40-42] and binds cell surface GAG [38]. Since cell surface receptors, such as VEGFR, bFGFR and TGFßR require GAG for optimal signaling [35-37], we-We thus investigate whether the presence of glycan-deficient PrP modulates cell signaling in the respective cell lines. We also delete KKRPK ( $\triangle \mathrm{KKRPK}$ ) on PrP to investigate if this domain is involved in the signaling. Unexpectedly, Cultured-when cells were cultured in FBS free condition, the glycan-deficient PrP cell lines consistently have higher levels of p-Akt (S473) compared to cells expressing WT PrP (Fig. 3A, top two panels). This enhancement requires the KKRPK motif of $\operatorname{PrP}$, which is essential for PrP to bind GAG [39]. In cells expressing similar level of cell surface DM- $\triangle$ KKRPK PrP (Fig. S1), the increase of p-Akt was absent (Fig. 3A, last lane of panels 1 and 2). We did not detect any significant changes in the levels of a | number of other signaling molecules, such as p-JNK (Fig. 3A, panels 3 and 4).

The PI3 kinase is required for the production of PIP3 from PIP2 to target Akt to | the cell surface [43-45]. To prove-seek additional support for our conclusion that the activation of $\mathrm{p}$-Akt is $\mathrm{PI} 3 \mathrm{~K}$ dependent, we treated the $\mathrm{PrP}$ expressing $\mathrm{CHO}$ cells with LY294002, an inhibitor of PI3 kinase, we used cells treated with DMSO as negative controls. as a negative control for the inhibitor, we treated the cells with the same amount of DMSO. We found that cells treated with LY294002 but not DMSO had significantly reduced p-Akt level (Fig. 3A, bottom two panels). Thus, glycan-deficient PrP can initiate PI3K-Akt signaling in an autocrine mode, without exogenous signal.

Some receptor tyrosine kinases depend on p-Akt for downstream signaling [43, 44]. We used a panel of tyrosine kinase inhibitor to identify the receptor that is 

inhibited the p-Akt signaling (Fig. 3B, panels 1, 2 and panels 5, 6). Since Axitinib (an inhibitor for VEGFR, PDGFR, or c-Kit) and Ki8751 (an inhibitor for VEGFR2) significantly reduce p-Akt level whereas ZM306416 (an inhibitor for VEGFR1) and SAR 131675 (an inhibitor for VEGFR3) do not alleviate phosphorylation of Akt (Fig. 3B, panels 3, 4 and panels 7, 8), we posithypothesize that VEGFR2 is probably likely to be the receptor engagedinvolved. The other tested inhibitors, such as AG490, BGJ398, BMS754807, Crizotinib, Mubritinib, and RGD did not show inhibitory effect (Fig. 3C).

$\mathrm{CHO}$ cells are known to express VEGFR2 and produce VEGF [46]. We then investigated whether PrP and VEGFR2 were co-localized. We found that more PrP immunoreactivity was associated with VEGFR2 in cells with glycan-deficient PrP than in cells with WT PrP-cells (Fig. 4A). This observation was further confirmed by co-IP experiments. By co-immunoprecipitation (co-IP), we-We demonstrated an interaction between glycan-deficient PrP and VEGFR2. found that an Antianti-VEGFR2 antibody brought down much more unglycosylated PrP from N181A and DM cells compared to PrP from WT and DM- $\triangle$ KKRPK cells (Fig. 4B, upper panels). Control antibody did not pull down unglycosylated $\operatorname{PrP}$ under the same condition (Fig. S2). Since KKRPK domain is required for binding between PrP and GAG, this result suggests-provide additional evidence that the interaction between glycan-deficient PrP and VEGFR2 is mediated by GAG. To avoid the possibility that more unglycosylated PrP pulled down was due to stickiness of the protein, we also used rabbit $\lg G$ as a negative control for antiVEGFR2 antibody, control antibody did not pull down unglycosylated PrP under the same condition (Fig. S2) thus supporting that the interaction between PrP and VEGFR2 is specific. Furthermore, in cells with glycan-deficient PrP there is more p-VEGFR2 ${ }_{2}$ indicating the activation of the receptor (Fig. 4B, bottom panels); ; indicating VEGFR2 activation in glycan-deficient PrP $\mathrm{CHO}$ cells under serum free condition.

Accordingly, The involvement of VEGFR2 in this signaling scheme was further confirmed by siRNA knocking-down of VEGFR2 in DM PrP expressing CHO cells. 
These cells showalso reduces-reduced the-level of p-Akt (Fig. 4C). Collectively, these results suggested that glycan-deficient PrP, GAG and VEGFR2 work in concert to promotepromoting the phosphorylation of Akt.

To further prove GAG is mediating the signaling_cascade, we double stained

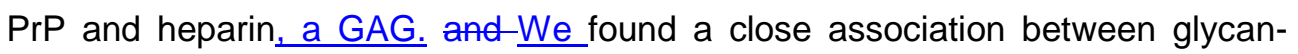
deficient PrP and heparin (Fig. 5A). Furthermore, When when glycan-deficient PrP cells were treated with heparinase, the levels of $p$-Akt were reduced (Fig. 5B $\underline{C}$ ). Densitometry measurement confirmed that $p$-Akt level was reduced after heparinase treatment (Fig. 56)-We posit that such a reduction in p-Akt level after heparinase treatment is due to a reduced PrP-GAG interaction.

Additional evidence supporting a role for supports that-GAG-played a role in this signaling scheme came from experiments using the pgsA-745 cell line, which is a CHO-K1 derived cell line deficient in GAG synthesis [47]. We transfected WT-_PrP or DM PrP into this cell line and sorted out-selected transfected cells with similar surface PrP expression by flow cytometry (Fig. 5D, left panel). Immunoblotting confirmed that the PrP expression is similar for WT PrP and DM PrP in these cells (Fig. 5D, right panel). However, expression of DM PrP in pgs745 cell line did not up-regulate p-Akt (Fig. 5E), thus supporting that GAG is required for activation of PI3K-Akt pathway in $\mathrm{CHO}$ cells expressing glycandeficient PrP.

\subsection{Being GPI-anchored and in lipid rafts are essential for PrP to participate in signaling}

Since receptor tyrosine kinase activation requires lipid raft localization_[48, 49], we then investigated whether being GPI anchored and in lipid raft were important | for glycan-deficient PrP-stimulated signaling to participate in activating VEGFR2. We generated different chimeric PrP proteins containing the extracellular domain of PrP fused to the transmembrane and cytoplasmic domains of human CD4 (Fig. 6A). We then sorted out-selected for cells with similar level of surface PrP by flow cytometry using 4H2 Mab (Fig. 6B). Immunoblotting showed that those chimeric 
PrP-CD4 and GPI anchored-PrP cells appear to express comparable level of PrP (Fig. 6C). However, the co-location of DM-CD4 and GM1 is reduced compare to DM PrP and GM1 (Fig. 6D). Correspondingly, much less DM-CD4 protein is present in the lipid raft fractions (Fig. 6E, fractions 3-5). More importantly, the enhancements of $p$-Akt levels are-were significantly diminished in cells bearing glycan-deficient chimeric CD4-PrP (Fig. 6F, G). These results prove are consistent with our hypothesis that being GPI anchored and localizing in lipid raft is are important for glycan-deficient $\operatorname{PrP}$ to participate in the activation of VEGFR2 signaling.

\subsection{Under glycosylated PrP cells-Cells bearing Glycan-deficient PrP are more adhesive and migratory in vitro}

Finally, we investigated the biological consequences of expressing glycan-

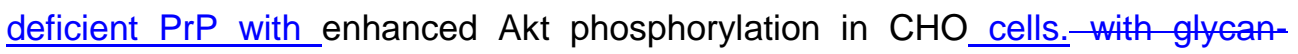
deficient PrP. CHO cells with glycan-deficient PrP are more adhesive (Fig. 7A) and migrate faster in a wound healing assay compared to cells with WT PrP (Figs. (7B and S3) $)_{\overline{5}}$ and-Accordingly, the enhanced motility also requires the presence of GAG binding domain, KKRPK, in the N-terminus of DM PrP.

\section{Discussion}

PrP exist as three glycoforms (di-glycosylated, mono-glycosylated or unglycosylated) in many types of cells. Whether the $\mathrm{N}$-linked glycans affect the physiological functions of PrP remains unknown. Here we take advantage of $\mathrm{CHO}$ cells which do not express endogenous PrP by expressing different glycan mutants to answer this question. The reason for N181A and DM PrP have lower apparent molecular weight than N197A and PNGase F treated WT PrP is not known. It may be because those mutations cause conformation change thus affecting protein migration even under SDS treatment. However, those differences are not responsible for the alterations in signal transduction because 
N197A, the same as N181A and DM, also activates PI3K-Akt signaling pathway Whether the two highly conserved $\mathrm{N}$-linked glycans are important in the expression of PrP on the cell surface is controversial [15-18]. Based on the results presented here, it is clear that the glycans are not essential for the expression of human PrP on the surface of $\mathrm{CHO}$ cells (Fig. 1B, C). While most of the glycan-deficient PrP species migrated according to their molecular masses in SDS-PAGE, the single mutant N181A appears to migrate a bit faster than the other single mutant, N197A (Fig. 1D, E). The reason for this discrepancy is not known. However, this motility difference in SDS-PAGE cannot account for the results seen in all subsequent experiments. All glycan-deficient PrP, including N181A, show comparable results (Figs 3 and $6 \mathrm{~F}$ ).

We provided evidence that in $\mathrm{CHO}$ cells, the $\mathrm{N}$-linked glycans are not essential for human PrP cell surface expression. By flow cytometry, we found that glycan deficiency does not affect the cell surface expression of PrP (Fig. 1B, C), and deletion of the GAG binding domain of PrP does not affect its cell surface expression (Fig. S1). It is worth noting that mutations of mouse PrP glycosylation sites abolish the cell surface expression of mouse PrP [16]. This discrepancy may be due to differences in human and mouse PrP or due to the differences in CHOcell lines used.

Earlier studies suggested that GPI-anchored proteins exist in the cell membrane as small aggregates composing from 4 to $15 \mathrm{GPI}$ anchored proteins $[50,51]$. In $\mathrm{CHO}$ cells, more glycan-deficient PrP is found in lipid raft (Fig. 2). We envision that without the negatively charged, repulsive glycans on PrP, more PrP are packed in the lipid raft. If our hypothesis is correct, the lipid raft should accommodate more glycan-deficient GPI anchored proteins. Prion infection requires the presence of $\mathrm{PrP}^{\mathrm{SC}}$ in lipid raft [52], which may convert lipid raft associated $\operatorname{PrP}^{C}$ on cell surface [53]. Our results thus support the cell model of $\mathrm{PrP}$ infection that unglycosylated $\mathrm{PrP}$ promotes accumulation of $\mathrm{PrP}^{\mathrm{SC}}$ in cultured cells [16].

Most interestingly, expression of glycan-deficient $\mathrm{PrP}$ in $\mathrm{CHO}$ cells enables $\underline{\mathrm{CHO} \text { cells to initiate autocrine signaling involving PrP, GAG and VEGFR2 (Figs } 3,}$ 
4 and 5). This interpretation is supported by multiple lines of evidence: 1) $\mathrm{CHO}$ cells expressing DM- $\triangle K K R P K$ PrP, which is unable to bind GAG is unable to upregulate p-Akt (Fig. 3) ; 2) PrP, VEGFR2 and GAG are physically co-localized in lipid rafts(Figs. 4A, B and 5A); 3) down regulation of VEGFR2 by shRNAi in glycan-deficient cells reduces signal transduction(Fig. 4C); 4) treatment of DM PrP expressing cells with heparinase to remove GAG, reduces the levels of signaling(Fig. 5B, C); 5) expressing DM PrP in GAG deficient pgsA-745 cells does not show increase in PI3K-Akt signaling compare to WT PrP expressing pgsA-745 cells (Fig. 5D, E).

Besides packed more in lipid raft, glycan-deficient $\mathrm{PrP}$ activates $\mathrm{CHO}$ cells with enhanced signaling, involving PrP, GAG and VEGFR2 (Figs 3, 4 and 5). The underlying mechanism responsible for initiating the signaling has not been established. Binding GAG is important because $\mathrm{CHO}$ cells expressing DM$\triangle K K R P K$ PrP is unable to up-regulate p-Akt (Fig. 3). Treatment of DM PrP expressing cells with heparinase reduces the levels of signaling and expressing DM PrP in GAG deficient $\mathrm{CHO}$ cells does not activate PI3K-Akt signaling compare to WT PrP expressing pgsA745 cells (Fig. 5). Bridging by GAG that is anchored by UG PrP may change the half-life of cell surface VEGFR2 thus altering the rate of its endocytosis, a critical factor in VEGFR2 biology [54-56]. By trapping VEGF, GAG may enable VEGFR2 to respond to lower levels of VEGF, or GAG may recruit VEGFR2 in close domains in cells with lower density surface VEGFR2, thus facilitating the signaling. In addition, being GPI-anchored is also important for signaling. UG PrP bearing a transmembrane and cytoplasmic domain of CD4 does not localize in the lipid raft and shows reduced $p$-Akt signaling compared to GPI anchored UG PrP (Fig. 6).

VEGFR2 promotes cellular survival, migration and differentiation, and actin eytoskeleton organization [54,57]. Our observations that $\mathrm{CHO}$ cells bearing glycan-deficient PrP are more adhesive and migratory are consistent with the known functions of VEGFR2. Based on these observations, we propose a model to account for the observations reported here (Fig. 7C). In this model, glycandeficient PrP with its $\mathrm{N}$-terminal KKRPK domain can bind more cell surface $\mathrm{GAG}$ 
and VEGFR2 thus activating VEGFR2 signaling. However, when the $\mathrm{N}$-linked glycans are present or the GAG binding domain, KKRPK is absent in UG PrP, the interactions among UG PrP, GAG, and VEGFR2 are inhibited.

The exact nature of the GAG on the cell surface that facilitates PrP and VEGFR2 signaling is not known. The anti-heparin Mab used in this study reacts with both heparin and heparan sulfate. The heparinase preparation used also contains both heparinase and heparanase. Additional biochemical studies will be needed to identify whether the GAG in this scheme is free $G A G$ or proteoglycans associated GAG on the cell surface.

All CHO cells bearing glycan-deficient PrP (N181A, N197A and DM) -show enhanced $p$-Akt signaling. However, by co-IP, VEGFR2 pulls down only UG PrP but not MG PrP. The reason for this discrepancy is not clear. As determined by cell surface biotinylation, less than $5 \%$ of the total WT PrP on the cell surface is unglycosylatedUG whereas on the cell surface the amount of UG PrP is increased to about 15 to $20 \%$ in the MG PrP (Fig.8_ S4). VEGFR2 may interact preferentially with UG PrP; the reason that cells bearing MG PrP also show enhanced signaling is due to the proportional increase in the level of UG PrP on the cell surface.

Furthermore, it appears that the levels of $p$-Akt are comparable between cells bearing MG PrP and UG PrP, suggesting that the VEGFR2 signaling has reached plateau, we-We posit that the limiting factor may be the levels of VEGFR2 expression in $\mathrm{CHO}$ cells. While we were able to consistently pull down PrP using anti-VEGFR2 antibody, we were unable to reliably pull down VEGFR2 using anti-PrP antibody; indicating that the level of PrP is much higher than that of VEGFR2 in $\mathrm{CHO}$ cells.

The detail mechanism responsible for initiating this signaling cascade has not been established. The half-life of VEGFR2 on the cell surface is important in regulating VEGFR2 signaling (52-54). Bridging by GAG that is anchored by glycan-deficient PrP may alter the half-life of cell surface VEGFR2. Furthermore, since VEGF also binds GAG, cells surface GAG may be able to trap and concentrate VEGF, enabling VEGFR2 to respond to lower levels of VEGF. In 
addition, GAG can bring together VEGFR2 in cells that express low levels of VEGFR2, thus facilitating the signaling. Being GPI-anchored is also important for signaling. Glycan-deficient $\operatorname{PrP}$ bearing a transmembrane and cytoplasmic domain of CD4 does not localize in the lipid raft and shows reduced p-Akt signaling compared to GPI anchored glycan-deficient PrP (Fig. 6).

VEGFR2 promotes cellular survival, migration and differentiation, and actin cytoskeleton organization [54,57]. Our observations that $\mathrm{CHO}$ cells bearing glycan-deficient PrP are more adhesive and migratory are consistent with the known functions of VEGFR2. Based on these observations, we propose a model to account for the observations reported here (Fig. 7C). In this model, glycandeficient PrP with its N-terminal KKRPK domain can bind more cell surface GAG and VEGFR2 thus activating VEGFR2 signaling. However, when the $\mathrm{N}$-linked glycans are fully present, they somehow prevent the binding of the KKRPK domain to cell surface GAG, thus inhibiting the VEGFR2 activation.

The exact nature of the GAG on the cell surface that facilitates $\operatorname{PrP}$ and VEGFR2 signaling is not known. The anti-heparin Mab used in this study reacts with both heparin and heparan sulfate. The heparinase preparation used also contains both heparinase and heparanase. Additional biochemical studies will be needed to identify whether the GAG in this scheme is free GAG or proteoglycans associated GAG on the cell surface.

All our experiments were carried out in $\mathrm{CHO}$ cells. Whether our conclusions have in vivo significance remains to be determined. During normal aging in mice, the proportion of under glycosylated PrP is increased-increases [58]. PrP is also glycosylated differently in different cell types $[59,60]$. In human prion diseases, the ratios of DG, MG and UG PrP have long been considered to be important in the classification of human prion diseases [61, 62]; different PrP glycoforms may contribute to different aspects of the disease phenotype [19-21]. It has been reported that prion infection/conversion occurs in lipid raft [52, 53]. In cell model of $\operatorname{PrP}$ infection, unglycosylated $\operatorname{PrP}$ promotes accumulation of infectious prion in cultured cells [16]. Our finding that more glycan-deficient PrP are detected in lipid raft may provide an explanation for these findings. Finally, congenital disorder of 
glycosylation is a group of more than 75 human diseases, including immune deficiencies, inflammation, development as well as metabolic abnormalities [6365]. Aberrant protein glycosylation also contributes to tumor biology [66]. Any defects in glycosylation may alter the proportion of under glycosylated PrP contributing to pathogenesis.

\section{Acknowledgments}

This work was supported by grants from Chinese National Science Foundation (81172376, 31270209), Nature Science Foundation of Hubei Province (2015CFA087), Chinese Academy of Sciences (100-Talents Program), State Key Laboratory of Virology of China (2015IOV005), WIV "One-Three-Five" Strategic Programs.

We also thank Mr. Haojie Hao for scientific illustration of the proposed model. We thank The Core Facility and Technical Support, Wuhan Institute of Virology for technique support in Confocal Microscopy (Dr. Gao) and Flow Cytometry (Ms. Min).

\section{Competing interests}

The authors declare that they have no conflicts of interest with the contents of this article.

\section{Author contributions}

Z. G. and C. L. designed the research; Z. G. and C. L. performed the experiments; Z. G., H. Z., F. H., L. Y., X. Y., Y. Z., M. S., and C. L. analyzed the data and contributed reagents; Z. G., M. S., and C. L. wrote the paper. 


\section{References}

[1] N. Mitra, S. Sinha, T.N. Ramya, A. Surolia, N-linked oligosaccharides as outfitters for glycoprotein folding, form and function, Trends Biochem Sci, 31 (2006) 156-163. [2] A. Helenius, M. Aebi, Roles of N-linked glycans in the endoplasmic reticulum, Annu Rev Biochem, 73 (2004) 1019-1049.

[3] A. Tannous, G.B. Pisoni, D.N. Hebert, M. Molinari, N-linked sugar-regulated protein folding and quality control in the ER, Seminars in cell \& developmental biology, 41 (2015) 79-89.

[4] A. Varki, Biological roles of oligosaccharides: all of the theories are correct, Glycobiology, 3 (1993) 97-130.

[5] S.B. Prusiner, Prions, Proc Natl Acad Sci U S A, 95 (1998) 13363-13383.

[6] D.A. Harris, Cellular biology of prion diseases, Clinical microbiology reviews, 12 (1999) 429-444.

[7] J. Collinge, Prion diseases of humans and animals: their causes and molecular basis, Annual review of neuroscience, 24 (2001) 519-550.

[8] R. Linden, V.R. Martins, M.A. Prado, M. Cammarota, I. Izquierdo, R.R. Brentani, Physiology of the prion protein, Physiological reviews, 88 (2008) 673-728.

[9] D.R. Brown, K. Qin, J.W. Herms, A. Madlung, J. Manson, R. Strome, P.E. Fraser, T. Kruck, A. von Bohlen, W. Schulz-Schaeffer, A. Giese, D. Westaway, H. Kretzschmar, The cellular prion protein binds copper in vivo, Nature, 390 (1997) 684-687. [10] C. Gabus, S. Auxilien, C. Pechoux, D. Dormont, W. Swietnicki, M. Morillas, W. Surewicz, P. Nandi, J.L. Darlix, The prion protein has DNA strand transfer properties similar to retroviral nucleocapsid protein, Journal of molecular biology, 307 (2001) 1011-1021.

[11] X. Wang, F. Wang, L. Arterburn, R. Wollmann, J. Ma, The interaction between cytoplasmic prion protein and the hydrophobic lipid core of membrane correlates with neurotoxicity, The Journal of biological chemistry, 281 (2006) 13559-13565. [12] B. Caughey, K. Brown, G.J. Raymond, G.E. Katzenstein, W. Thresher, Binding of the protease-sensitive form of $\operatorname{PrP}$ (prion protein) to sulfated glycosaminoglycan and congo red [corrected], Journal of virology, 68 (1994) 2135-2141.

[13] A. Sailer, H. Bueler, M. Fischer, A. Aguzzi, C. Weissmann, No propagation of prions in mice devoid of PrP, Cell, 77 (1994) 967-968.

[14] P.M. Lledo, P. Tremblay, S.J. DeArmond, S.B. Prusiner, R.A. Nicoll, Mice deficient for prion protein exhibit normal neuronal excitability and synaptic transmission in the hippocampus, Proc Natl Acad Sci U S A, 93 (1996) 2403-2407.

[15] M. Rogers, A. Taraboulos, M. Scott, D. Groth, S.B. Prusiner, Intracellular accumulation of the cellular prion protein after mutagenesis of its Asn-linked glycosylation sites, Glycobiology, 1 (1990) 101-109.

[16] S. Lehmann, D.A. Harris, Blockade of glycosylation promotes acquisition of scrapie-like properties by the prion protein in cultured cells, The Journal of biological chemistry, 272 (1997) 21479-21487.

[17] S. Capellari, S.I. Zaidi, A.C. Long, E.E. Kwon, R.B. Petersen, The Thr183Ala Mutation, Not the Loss of the First Glycosylation Site, Alters the Physical Properties of the Prion Protein, Journal of Alzheimer's disease : JAD, 2 (2000) 27-35. 
[18] S.I. Zaidi, S.L. Richardson, S. Capellari, L. Song, M.A. Smith, B. Ghetti, M.S. Sy, P. Gambetti, R.B. Petersen, Characterization of the F198S prion protein mutation: enhanced glycosylation and defective refolding, Journal of Alzheimer's disease : JAD, 7 (2005) 159-171; discussion 173-180.

[19] F.K. Wiseman, E. Cancellotti, P. Piccardo, K. Iremonger, A. Boyle, D. Brown, J.W. Ironside, J.C. Manson, A.B. Diack, The glycosylation status of PrPC is a key factor in determining transmissible spongiform encephalopathy transmission between species, Journal of virology, 89 (2015) 4738-4747.

[20] E. Cancellotti, S.P. Mahal, R. Somerville, A. Diack, D. Brown, P. Piccardo, C. Weissmann, J.C. Manson, Post-translational changes to PrP alter transmissible spongiform encephalopathy strain properties, The EMBO journal, 32 (2013) 756769.

[21] N.L. Tuzi, E. Cancellotti, H. Baybutt, L. Blackford, B. Bradford, C. Plinston, A. Coghill, P. Hart, P. Piccardo, R.M. Barron, J.C. Manson, Host PrP glycosylation: a major factor determining the outcome of prion infection, PLoS biology, 6 (2008) e100. [22] S.A. Priola, V.A. Lawson, Glycosylation influences cross-species formation of protease-resistant prion protein, The EMBO journal, 20 (2001) 6692-6699.

[23] S. Lehmann, D.A. Harris, A mutant prion protein displays an aberrant membrane association when expressed in cultured cells, The Journal of biological chemistry, 270 (1995) 24589-24597.

[24] C. Campbell, P. Stanley, The Chinese hamster ovary glycosylation mutants LEC11 and LEC12 express two novel GDP-fucose:N-acetylglucosaminide 3-alpha-Lfucosyltransferase enzymes, The Journal of biological chemistry, 259 (1984) 1120811214.

[25] G. Zanusso, D. Liu, S. Ferrari, I. Hegyi, X. Yin, A. Aguzzi, S. Hornemann, S. Liemann, R. Glockshuber, J.C. Manson, P. Brown, R.B. Petersen, P. Gambetti, M.S. Sy, Prion protein expression in different species: analysis with a panel of new $\mathrm{mAbs}$, Proc Natl Acad Sci U S A, 95 (1998) 8812-8816.

[26] L. Yang, Y. Zhang, L. Hu, Y. Zhu, M.S. Sy, C. Li, A panel of monoclonal antibodies against the prion protein proves that there is no prion protein in human pancreatic ductal epithelial cells, Virologica Sinica, 29 (2014) 228-236.

[27] T. Liu, R. Li, T. Pan, D. Liu, R.B. Petersen, B.S. Wong, P. Gambetti, M.S. Sy, Intercellular transfer of the cellular prion protein, The Journal of biological chemistry, 277 (2002) 47671-47678.

[28] C. Li, S. Yu, F. Nakamura, S. Yin, J. Xu, A.A. Petrolla, N. Singh, A. Tartakoff, D.W. Abbott, W. Xin, M.S. Sy, Binding of pro-prion to filamin A disrupts cytoskeleton and correlates with poor prognosis in pancreatic cancer, The Journal of clinical investigation, 119 (2009) 2725-2736.

[29] C. Li, S. Yu, F. Nakamura, O.T. Pentikainen, N. Singh, S. Yin, W. Xin, M.S. Sy, Proprion binds filamin A, facilitating its interaction with integrin beta1, and contributes to melanomagenesis, The Journal of biological chemistry, 285 (2010) 30328-30339. [30] N. Naslavsky, R. Stein, A. Yanai, G. Friedlander, A. Taraboulos, Characterization of detergent-insoluble complexes containing the cellular prion protein and its scrapie isoform, The Journal of biological chemistry, 272 (1997) 6324-6331. [31] K. Simons, R. Ehehalt, Cholesterol, lipid rafts, and disease, The Journal of clinical investigation, 110 (2002) 597-603. 
[32] P.W. Janes, S.C. Ley, A.I. Magee, Aggregation of lipid rafts accompanies signaling via the T cell antigen receptor, The Journal of cell biology, 147 (1999) 447-461. [33] L.W. Ruddock, H.M. Webb, S.P. Ruston, C. Cheesman, R.B. Freedman, T.R. Hirst, $\mathrm{A} \mathrm{pH}$-dependent conformational change in the B-subunit pentamer of Escherichia coli heat-labile enterotoxin: structural basis and possible functional role for a conserved feature of the AB5 toxin family, Biochemistry, 35 (1996) 16069-16076. [34] E.A. Merritt, T.K. Sixma, K.H. Kalk, B.A. van Zanten, W.G. Hol, Galactose-binding site in Escherichia coli heat-labile enterotoxin (LT) and cholera toxin (CT), Molecular microbiology, 13 (1994) 745-753.

[35] M. Klagsbrun, Mediators of angiogenesis: the biological significance of basic fibroblast growth factor (bFGF)-heparin and heparan sulfate interactions, Seminars in cancer biology, 3 (1992) 81-87.

[36] J. Folkman, Y. Shing, Control of angiogenesis by heparin and other sulfated polysaccharides, Advances in experimental medicine and biology, 313 (1992) 355364.

[37] C.C. Rider, Heparin/heparan sulphate binding in the TGF-beta cytokine superfamily, Biochemical Society transactions, 34 (2006) 458-460.

[38] T. Pan, B.S. Wong, T. Liu, R. Li, R.B. Petersen, M.S. Sy, Cell-surface prion protein interacts with glycosaminoglycans, The Biochemical journal, 368 (2002) 81-90.

[39] S. Yin, N. Pham, S. Yu, C. Li, P. Wong, B. Chang, S.C. Kang, E. Biasini, P. Tien, D.A. Harris, M.S. Sy, Human prion proteins with pathogenic mutations share common conformational changes resulting in enhanced binding to glycosaminoglycans, Proc Natl Acad Sci U S A, 104 (2007) 7546-7551.

[40] S. Mouillet-Richard, M. Ermonval, C. Chebassier, J.L. Laplanche, S. Lehmann, J.M. Launay, O. Kellermann, Signal transduction through prion protein, Science (New York, N.Y.), 289 (2000) 1925-1928.

[41] L.B. Chiarini, A.R. Freitas, S.M. Zanata, R.R. Brentani, V.R. Martins, R. Linden, Cellular prion protein transduces neuroprotective signals, The EMBO journal, 21 (2002) 3317-3326.

[42] S.M. Zanata, M.H. Lopes, A.F. Mercadante, G.N. Hajj, L.B. Chiarini, R. Nomizo, A.R. Freitas, A.L. Cabral, K.S. Lee, M.A. Juliano, E. de Oliveira, S.G. Jachieri, A. Burlingame, L. Huang, R. Linden, R.R. Brentani, V.R. Martins, Stress-inducible protein 1 is a cell surface ligand for cellular prion that triggers neuroprotection, The EMBO journal, 21 (2002) 3307-3316.

[43] L.C. Cantley, The phosphoinositide 3-kinase pathway, Science (New York, N.Y.), 296 (2002) 1655-1657.

[44] B.A. Hemmings, D.F. Restuccia, PI3K-PKB/Akt pathway, Cold Spring Harbor perspectives in biology, 4 (2012) a011189.

[45] R.C. Delos Santos, C. Garay, C.N. Antonescu, Charming neighborhoods on the cell surface: plasma membrane microdomains regulate receptor tyrosine kinase signaling, Cellular signalling, 27 (2015) 1963-1976.

[46] U.M. Lim, M.G. Yap, Y.P. Lim, L.T. Goh, S.K. Ng, Identification of autocrine growth factors secreted by $\mathrm{CHO}$ cells for applications in single-cell cloning media, Journal of proteome research, 12 (2013) 3496-3510.

[47] J.D. Esko, T.E. Stewart, W.H. Taylor, Animal cell mutants defective in glycosaminoglycan biosynthesis, Proc Natl Acad Sci U S A, 82 (1985) 3197-3201. 
[48] K. Simons, D. Toomre, Lipid rafts and signal transduction, Nature reviews. Molecular cell biology, 1 (2000) 31-39.

[49] X. Sun, Y. Fu, M. Gu, L. Zhang, D. Li, H. Li, S. Chien, J.Y. Shyy, Y. Zhu, Activation of integrin alpha5 mediated by flow requires its translocation to membrane lipid rafts in vascular endothelial cells, Proc Natl Acad Sci U S A, 113 (2016) 769-774.

[50] P. Sharma, R. Varma, R.C. Sarasij, Ira, K. Gousset, G. Krishnamoorthy, M. Rao, S. Mayor, Nanoscale organization of multiple GPI-anchored proteins in living cell membranes, Cell, 116 (2004) 577-589.

[51] T. Friedrichson, T.V. Kurzchalia, Microdomains of GPI-anchored proteins in living cells revealed by crosslinking, Nature, 394 (1998) 802-805.

[52] G.S. Baron, K. Wehrly, D.W. Dorward, B. Chesebro, B. Caughey, Conversion of raft associated prion protein to the protease-resistant state requires insertion of PrP-res (PrP(Sc)) into contiguous membranes, The EMBO journal, 21 (2002) 10311040.

[53] A. Rouvinski, S. Karniely, M. Kounin, S. Moussa, M.D. Goldberg, G. Warburg, R. Lyakhovetsky, D. Papy-Garcia, J. Kutzsche, C. Korth, G.A. Carlson, S.F. Godsave, P.J.

Peters, K. Luhr, K. Kristensson, A. Taraboulos, Live imaging of prions reveals nascent PrPSc in cell-surface, raft-associated amyloid strings and webs, The Journal of cell biology, 204 (2014) 423-441.

[54] S. Sawamiphak, S. Seidel, C.L. Essmann, G.A. Wilkinson, M.E. Pitulescu, T. Acker, A. Acker-Palmer, Ephrin-B2 regulates VEGFR2 function in developmental and tumour angiogenesis, Nature, 465 (2010) 487-491.

[55] L.C. Ewan, H.M. Jopling, H. Jia, S. Mittar, A. Bagherzadeh, G.J. Howell, J.H. Walker, I.C. Zachary, S. Ponnambalam, Intrinsic tyrosine kinase activity is required for vascular endothelial growth factor receptor 2 ubiquitination, sorting and degradation in endothelial cells, Traffic (Copenhagen, Denmark), 7 (2006) 12701282.

[56] A. Horowitz, H.R. Seerapu, Regulation of VEGF signaling by membrane traffic, Cellular signalling, 24 (2012) 1810-1820.

[57] T.T. Chen, A. Luque, S. Lee, S.M. Anderson, T. Segura, M.L. Iruela-Arispe, Anchorage of VEGF to the extracellular matrix conveys differential signaling responses to endothelial cells, The Journal of cell biology, 188 (2010) 595-609.

[58] A.X. Goh, C. Li, M.S. Sy, B.S. Wong, Altered prion protein glycosylation in the aging mouse brain, Journal of neurochemistry, 100 (2007) 841-854.

[59] T. Liu, T. Zwingman, R. Li, T. Pan, B.S. Wong, R.B. Petersen, P. Gambetti, K. Herrup, M.S. Sy, Differential expression of cellular prion protein in mouse brain as detected with multiple anti-PrP monoclonal antibodies, Brain research, 896 (2001) 118-129.

[60] T. Pan, R. Li, B.S. Wong, T. Liu, P. Gambetti, M.S. Sy, Heterogeneity of normal prion protein in two- dimensional immunoblot: presence of various glycosylated and truncated forms, Journal of neurochemistry, 81 (2002) 1092-1101.

[61] P. Parchi, A. Giese, S. Capellari, P. Brown, W. Schulz-Schaeffer, O. Windl, I. Zerr, H. Budka, N. Kopp, P. Piccardo, S. Poser, A. Rojiani, N. Streichemberger, J. Julien, C. Vital, B. Ghetti, P. Gambetti, H. Kretzschmar, Classification of sporadic CreutzfeldtJakob disease based on molecular and phenotypic analysis of 300 subjects, Annals of neurology, 46 (1999) 224-233. 
[62] A.F. Hill, S. Joiner, J.D. Wadsworth, K.C. Sidle, J.E. Bell, H. Budka, J.W. Ironside, J. Collinge, Molecular classification of sporadic Creutzfeldt-Jakob disease, Brain : a journal of neurology, 126 (2003) 1333-1346.

[63] J. Bjorkqvist, S. de Maat, U. Lewandrowski, A. Di Gennaro, C. Oschatz, K. Schonig, M.M. Nothen, C. Drouet, H. Braley, M.W. Nolte, A. Sickmann, C. Panousis, C. Maas, T.

Renne, Defective glycosylation of coagulation factor XII underlies hereditary angioedema type III, The Journal of clinical investigation, 125 (2015) 3132-3146. [64] J. Jaeken, Congenital disorders of glycosylation, Handbook of clinical neurology, 113 (2013) 1737-1743.

[65] H.H. Freeze, Update and perspectives on congenital disorders of glycosylation, Glycobiology, 11 (2001) 129r-143r.

[66] S.R. Stowell, T. Ju, R.D. Cummings, Protein glycosylation in cancer, Annual review of pathology, 10 (2015) 473-510. 


\section{Figure Captions}

Fig. 1. Expressing of WT, N181A, N197A and DM PrP in CHO cells. (A) The drawing of PrP shows the locations of the two N-linked glycosylation sites, and the locations of the epitopes recognized by the panel of anti-PrP Mabs $4 \mathrm{H} 2$ and $7 \mathrm{~A} 12$ used in this study. (B) Flow cytometry analysis with different anti-PrP Mabs reveals similar cell surface PrP expression. Using different anti-PrP Mabs, 4H2 and 7A12, all four cell lines appear to have comparable levels of cell surface PrP. BG: background, empty vector transfected $\mathrm{CHO}$ cells stained with PrP specific Mabs as indicated. (C) Live cells staining with Mab 4H2 shows similar amount of cell surface PrP expression. Cells were stained with anti-PrP Mab 4H2 (red) at $4^{\circ} \mathrm{C}$. The nuclei were counter stained with DAPI as described. Scale bars: $10 \mu \mathrm{m}$. (D) PrP glycosylation mutants are expressed in $\mathrm{CHO}$ cells at similar level. Immunoblotting of cell lysates from the parental $\mathrm{CHO}$ cells; $\mathrm{CHO}$ cells with wild type PrP (WT); CHO cells with PrP-N181A_(N181A); CHO cells with N197A (N197A) or CHO cells with the double mutant_(DM) lacking both glycosylation sites with anti-PrP Mab 4H2. WT PrP contains three PrP isoforms: diglycosylated (DG), mono-glycosylated (MG) and unglycosylated (UG) PrP. While the two single site mutants have MG and UG PrP. The double mutant (DM) only has UG PrP. (E) Immunoblotting of cell lysates from various cell lines after treatment with endoglycosidase $F$ (PNGase F) to remove the glycans with Mab 4H2. PNGase $F$ treated N181A and DM PrP proteins migrated slightly faster than PNGase F treated N197A and WT PrP.

Fig. 2. More glycan-deficient PrP are partitioned in lipid rafts. (A) Cell lysates | were prepared from cells expressing either WT or DM PrP-cells and then fractionated as described. The collected fractions were then immunoblotted with either an anti-flotillin-1 Mab (FLOT 1) or an anti-PrP Mab 4H2 (PrP). While the levels of flotillin-1 were comparable between cells bearing WT PrP WT and DM PrP DM in the lipid raft associated fractions (Fractions 3-5, panels 1 and 3), the amount of PrP in these fractions (Fractions 3-5, comparing panels 2 and 4) were 
| greatly increased in the lysate from DM cells than from WT PrP-Cells. (B) The summary and densitometry quantification of 6 different fractionation experiments showing that the amounts of glycan-deficient PrP in the lipid raft fractions (Fractions 3-5) in DM cells were significantly higher than in the corresponding fractions from WT cells. (C) Confocal images showing co-localization of DM PrP DM (red) and GM1 as revealed by staining with cholera toxin (green) in DM cells (arrows point to the co-location of $\operatorname{PrP}$ and GM1). Scale bars: $10 \mu \mathrm{m}$. (D) Pearson's correlation showed significantly more co-location of DM PrP and GM1 co-tocalize than co-location of WT PrP and GM1-co-tocalize. The results represent 30 cells randomly collected from 11 images.

Fig. 3. Cells expressing glycan-deficient PrP show activated PI3K-Akt. (A) Cells lysates were prepared from the indicated cell lines cultured in serum free medium and then immunoblotted with antibodies against p-Akt (S473), Akt, pSAPK/JNK (Thr183/Tyr185) or SAPK/JNK. All cells bearing glycan-deficient PrP have higher levels of p-Akt (panel 1) but not Akt (panel 2), p-SAPK/JNK (Thr183/Tyr185) (panel 3) or SAPK/JNK (panel 4). This enhanced p-Akt is absent in DM- $\triangle K$ KKRPK cells (panel 1, last lane). Activation of $p$-Akt is inhibited by PI3K inhibitor LY294002 (panels 7 and 8), but not by DMSO (panels 5 and 6). (B) Inhibitors of VEGFR prevent increase in p-Akt in cells bearing glycan-deficient $\operatorname{PrP}$ (panels 1 and 5). All cells were cultured in serum free medium and incubated with various chemical inhibitors as described in Material and Methods. Cell lysates were prepared at the end of culture and immunoblotted with either anti-pAkt (S473) or anti-Akt. Only inhibitors of VEGFR (panel 1) or VEGFR2 (panel 5) but not VEGFR1 (panel 3) or VEGFR3 (panel 7) diminish the levels of p-Akt in cells bearing glycan-deficient PrP. (C) The other tested non-VEGFR2 inhibitors (AG490, BGJ398, BMS754807, Crizotinib, Mubritinib, and RGD) at the indicated concentrations did not attenuate p-Akt signaling in N181A, N197A, and DM PrP expressing $\mathrm{CHO}$ cells. The experiments were repeated three times with similar results. 

domain. (A) Confocal images showed the co-location of glycan-deficient PrP and VEGFR2 in DM cells. WT and DM cells were stained with anti-PrP Mab 4H2 (red) or anti-VEGFR2 antibody (green) and viewed in a confocal microscopy. More colocation of PrP and VEGFR2 were seen in DM cells compared to WT cells (arrows point to the co-location of $\operatorname{PrP}$ and VEFGR2, comparing to right panels columns). Scale bars: $10 \mu \mathrm{m}$. (B) PrP co-immunoprecipitated with VEGFR2 in glycan-deficient cells but not in cells with WT PrP. The amount of PrP coimmunoprecipitated with VEGFR2 is greatly reduced in DM- $\triangle$ KKRPK cells (last lane of top panel). Total VEGFR2 pulled down by the antibody were shown | (second row of top panel) to indicate similar amount of_teadingloading. IgG heavy chain used for co-IP is revealed to show similar amount of antibody used for co-IP (third row of top panel). P-VEGFR2 was activated in glycan-deficient PrP cells and the activation required KKRPK (last lane of bottom panel). Quantification of amount PrP was pulled down by VEGFR2 based on | densitometry_(top right panel) and quantification of p-VEGFR2 from $\mathrm{CHO}$ cells expressing different forms of PrP based on densitometry (bottom right panel). The experiments were repeated three times with similar results. (C) Knockdown VEGFR2 in DM PrP CHO cells reduces p-Akt level. Immunoblotting with antiVEGFR2 specific polyclonal antibody confirmed the reduction of VEGFR2 in siRNA knocking down DM PrP CHO cells using four different siRNA sequences (1 to 4) (panel 1). Activation of Akt is reduced when VEGFR2 is down regulated (panel 2). Quantification of VEGFR2 and p-Akt levels in various VEGFR2 down regulated cells based on densitometry using image $\mathrm{J}$ (Bottom panels). The experiments were repeated three times with similar results.

Fig. 5. The GAG binds glycan-deficient PrP to stimulate signaling. (A) Confocal images showed more co-location of glycan-deficient PrP and heparin in DM cells (right panel) than in WT cells (left panel). WT and DM cells were stained with anti-PrP Mab bio-4H2 (green) or anti-heparin Mab (red) and viewed in a confocal microscopy (arrows point to the co-location of PrP and heparin). Scale 
bars: $10 \mu \mathrm{m}$. (B) Treatment of glycan-deficient PrP cells cultured in FBS free medium with heparinase decreases Akt phosphorylation compare to control vehicle treated cells. (C) Quantification of results in (B) from four different experiments based on densitometry revealed a significant reduction (25-30\%) of p-Akt after heparinase treatment. (D) Expressing of DM PrP in GAG deficient pgsA-745 cells did not elevate $p$-Akt signaling compare to WT PrP. Expression of comparable levels of WT and DM PrP on the cell surface of transfected pgsA-745 cells based on 4H2 staining (left panel); BG: background, empty vector transfected pgsA-745 cells stained with $4 \mathrm{H} 2$. Immunoblotting with PrP specific Mab $4 \mathrm{H} 2$ confirmed the expression of WT and DM PrP in pgsA-745 cells (right panel). (E) Expression of DM PrP in pgsA-745 cells did not increase the level of p-Akt (right two lanes) whereas DM PrP expressed in GAG sufficient $\mathrm{CHO}$ cells did activate Akt compare to WT PrP (left two panels). The experiments were repeated three times with similar results.

Fig. 6. GPI anchor is essential for glycan-deficient PrP to engage in PI3K-

Akt signaling. (A) Drawings of various PrP-CD4 transmembrane and cytoplasmic domain chimeric proteins. (B) Flow cytometry analysis revealed that the PrP-CD4 chimeric proteins (WT-CD4, DM-CD4) were detectable on the cell surface, and had similar expression level as GPI anchored PrP (WT, DM) as stained with anti-PrP Mab 4H2. BG: background, empty vector transfected $\mathrm{CHO}$ cells stained with $4 \mathrm{H} 2$. (C) Immunoblotting with anti-PrP Mab $4 \mathrm{H} 2$ revealed the presence of the chimeric proteins (WT-CD4, N181A-CD4, N197A-CD4, DM-CD4)

| in various cell lines. The Mol. Mass of the chimeric protein is about $10 \mathrm{Kda}-\mathrm{kDa}$ larger than the WT PrP due to the inclusion of the CD4 transmembrane and cytoplasmic domain. (D) Confocal images showing less PrP-CD4 chimeric proteins (WT-CD4, N181A-CD4, DM-CD4) co-localize with GM1 if the GPI anchor was replaced with CD4 transmembrane domain. WT-CD4, N181A-CD4, and DM-CD4 cells were stained with anti-PrP Mab 4H2 (green) or cholera toxin (red) to label GM1, and viewed in a confocal microscopy (arrows point to the colocation of PrP and GM1). Scale bars: $10 \mu \mathrm{m}$. (E) The amount of DM-CD4 
chimeric protein found in lipid rafts (fractions 3-5, top panel) was greatly reduced compared with GPI anchored DM PrP (bottom panel). Cell lysates were fractionated and each fraction was immunoblotted with anti-PrP Mab 4H2. (F) Being GPI-anchored was important in enhancing p-Akt. The levels of $p$-Akt were reduced in cells bearing glycan-deficient PrP-CD4 chimeric proteins (labelled as CD4) compared with cells with corresponding GPI anchored PrP (labelled as GPI). (G) Quantification of results in (F) based on densitometry showed a $25-50 \%$ reduction of $\mathrm{p}$-Akt level in PrP-CD4 chimeric protein expressing cells than in GPI anchored PrP expressing cells. The experiments were repeated twice with similar results.

\section{Fig. 7. MG and UG PrP cells tend to spread and migrate faster than WT PrP} cells. (A) Significantly faster spreading of MG and UG PrP cells on heparin coated glass bottom petri dish $(n=3, p<0.05$ ) comparing WT to MG and UG PrP expressing cells). (B) N181A and UG PrP cells migrated significantly faster than DG PrP and DM- $\triangle$ KKRPK PrP cells $(n=5, p<0.05)$. (C) A model proposed to explain UG PrP when localizing in lipid raft could bind GAG and activate VEGFR2, thus activating PI3K-Akt pathway. N-linked glycans prevent the binding between PrP and VEGFR2 or VEGFR2 and GAG (left panel). GAG binding domain at the N-terminus of $\operatorname{PrP}$ (orange colored) is required for $\operatorname{PrP}, \mathrm{GAG}$, and VEGFR2 signaling. Without this domain PrP can not interact with GAG (middle panel). Glycan-deficient PrP forms complex with GAG and VEGFR2 thus activating PI3K-Akt signaling pathway (right panel).

Fig. 8. Much more unglycosylated PrP is present on SM PrP cell surface than on WT PrP surface. (A) Cell surface molecules were biotin labeled (bio) and pulled down by streptavidin beads. The total PrP was then detected with $\mathrm{Aab}-4 \mathrm{H} 2$. It turns out that higher percentage of unglycosylated PrP is present on the cell surface of N181A PrP expression cells than on WT PrP cells. CK: cell lysate was detected by $4 \mathrm{H} 2$; Bio: biotin labelled cell surface protein was detected by $4 \mathrm{H2}$. (B) Quantification of percentage of di-glycosylated PrP, mono- 
Fig 1

\begin{tabular}{|c|c|c|c|c|c|c|c|}
\hline \multirow[t]{3}{*}{ A } & \multicolumn{6}{|c|}{$\mathrm{N}$-linked glycans } & 231 \\
\hline & KKRPK & B1 & at & 82 & $\alpha 2$ & $\alpha 3$ & \multirow[b]{2}{*}{ GPI anchor } \\
\hline & \multicolumn{6}{|c|}{$\begin{array}{cc}7 \mathrm{~A} 12 & \text { 4H2 } \\
(146-158) & (150-160)\end{array}$} & \\
\hline
\end{tabular}
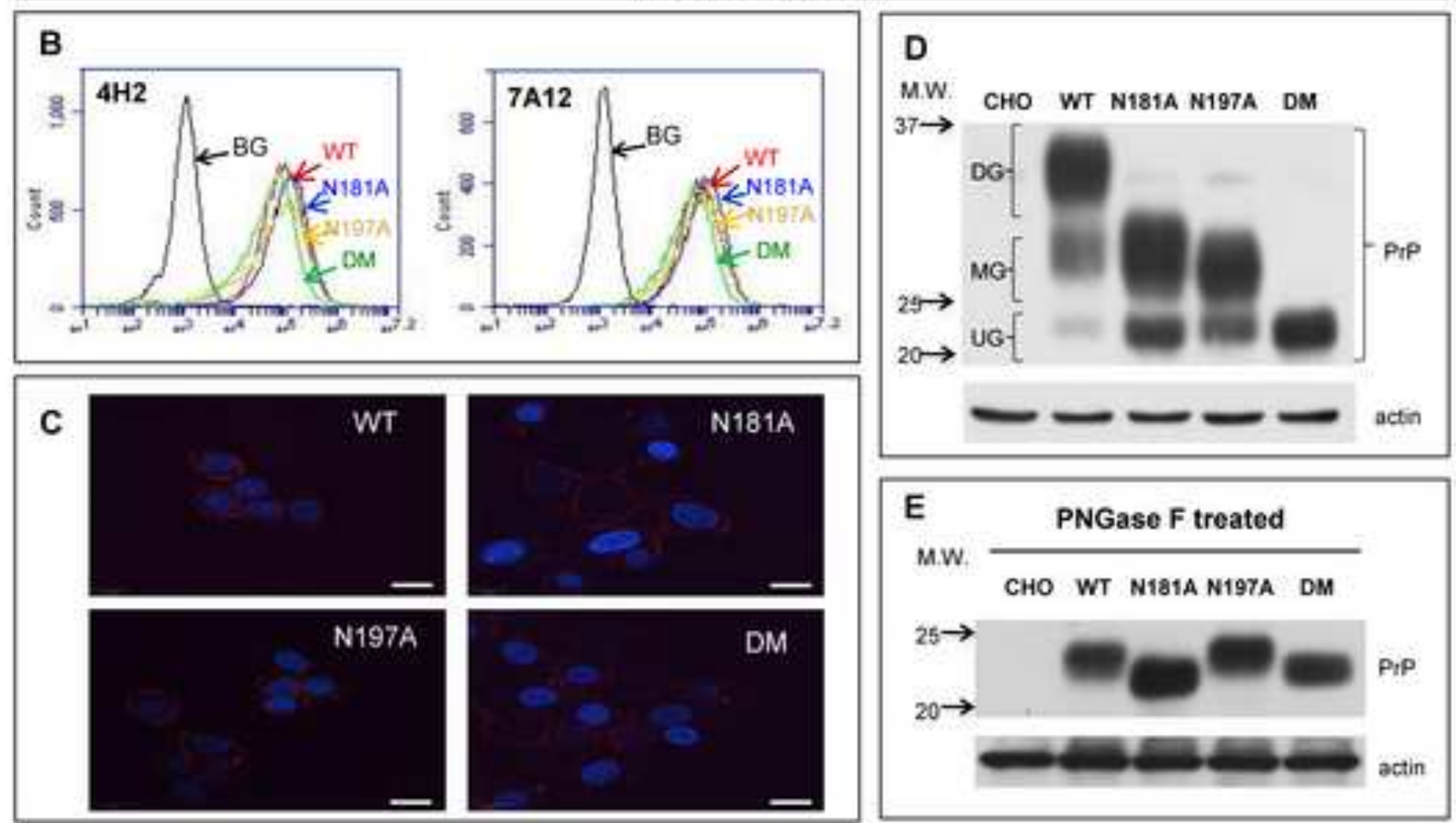
Click here to download high resolution image

Fig 2
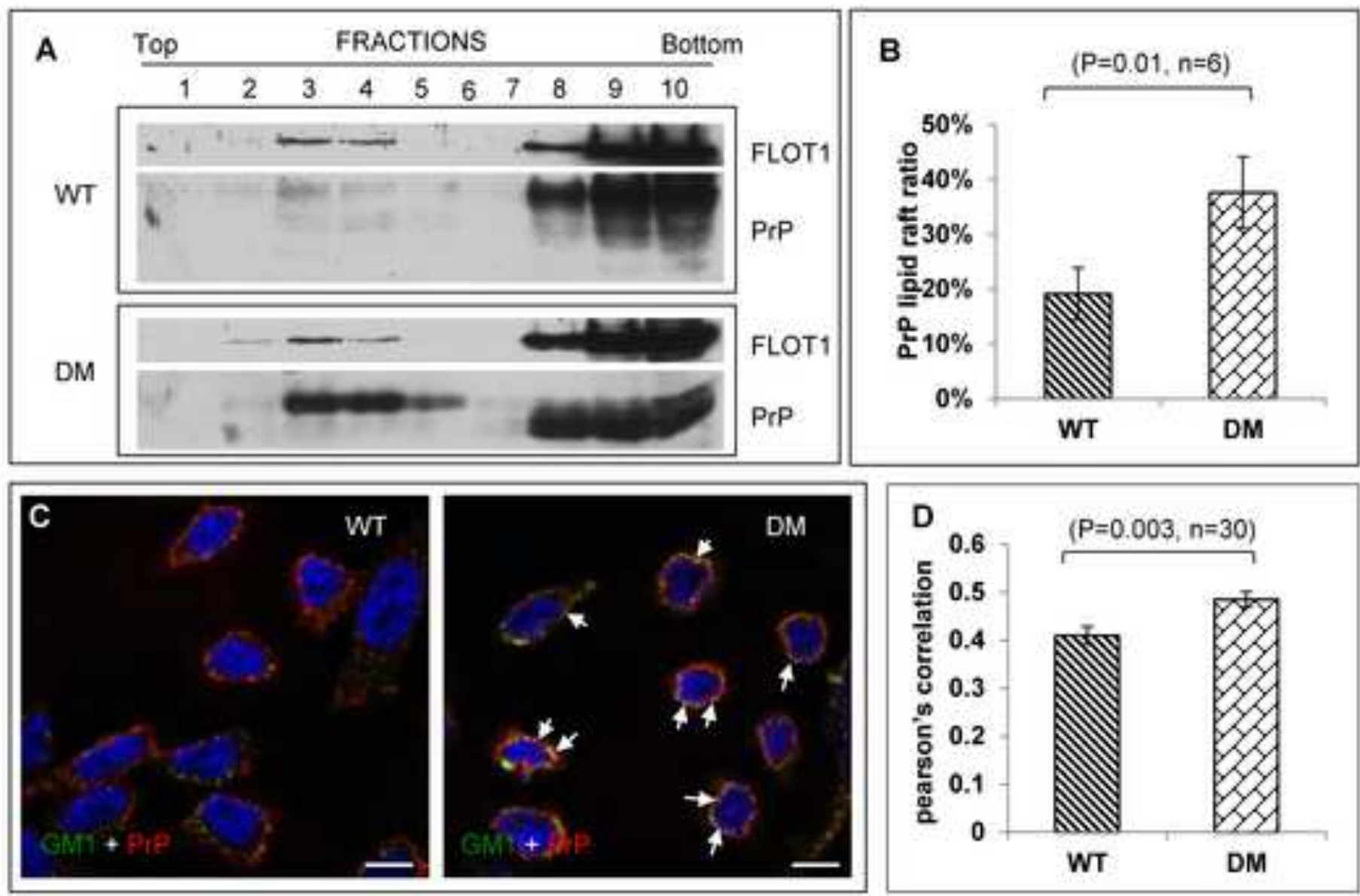
Click here to download high resolution image

Fig 3

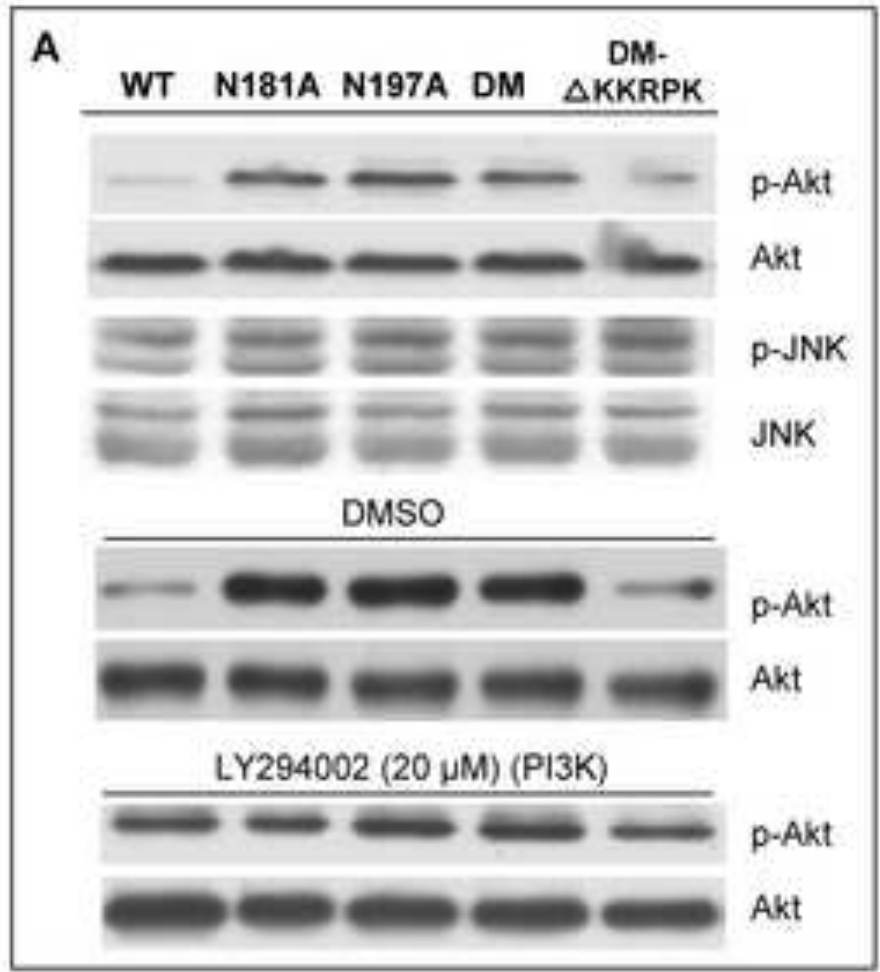

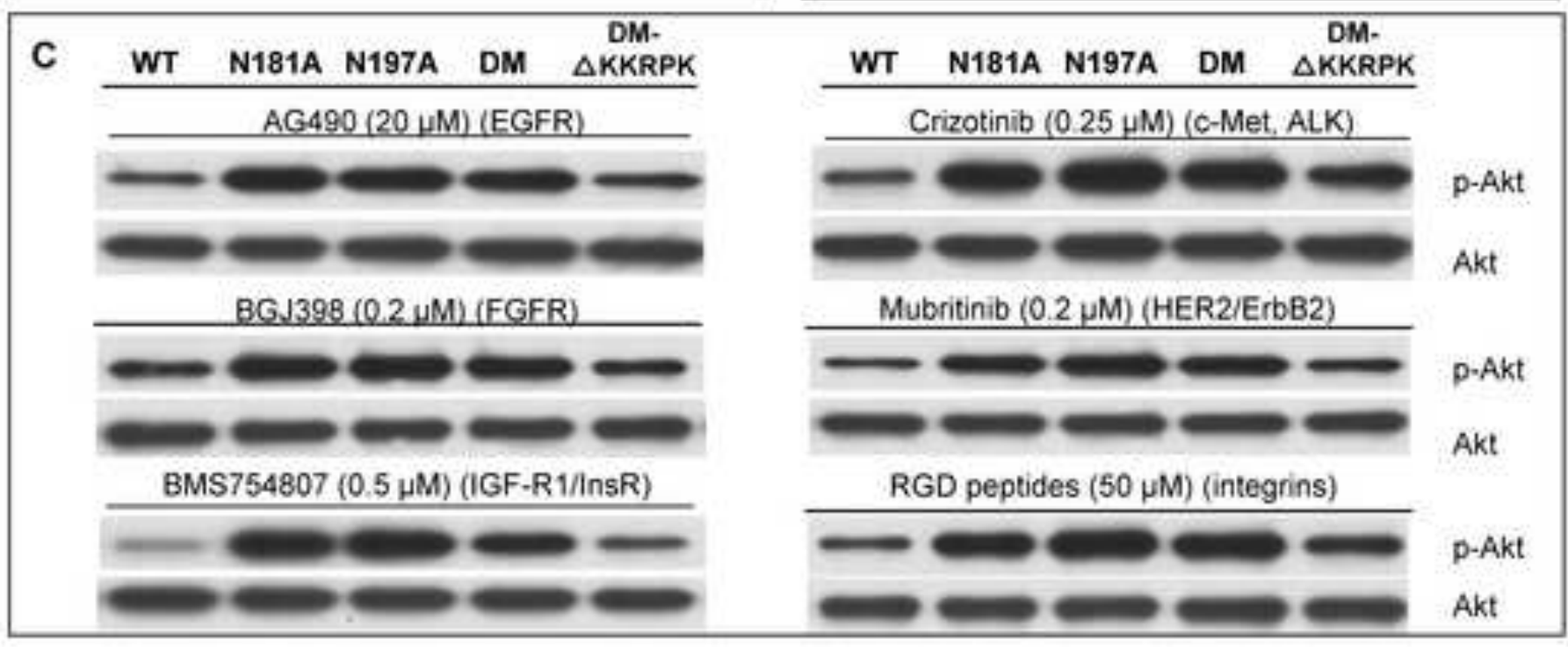

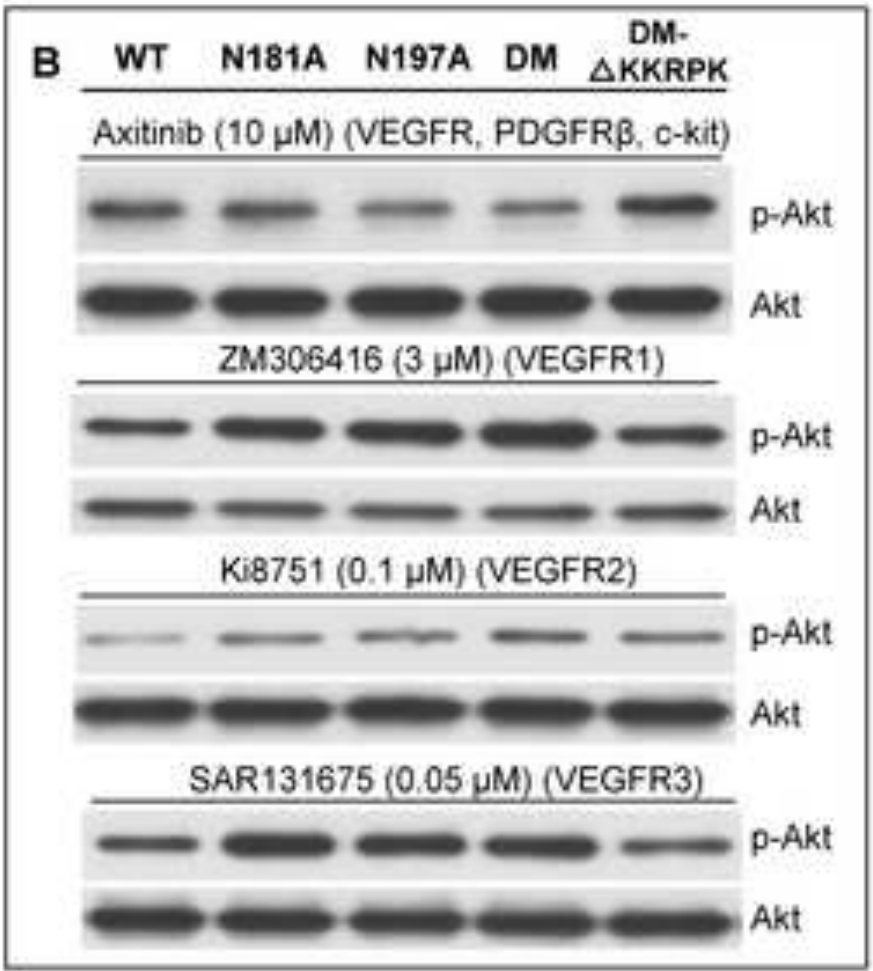

Crizotinib $(0.25 \mu \mathrm{M})$ (c-Met, ALK)

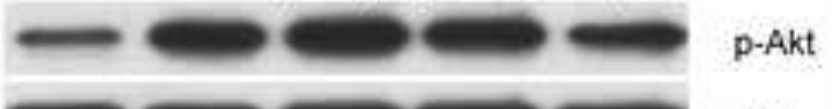

Akt

Mubritinib (0.2 UM) (HER2/ErbB2)

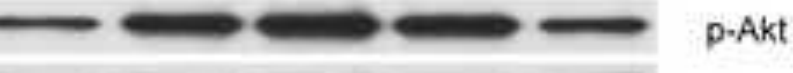

Akt

-Akt

Akt 
Fig 4
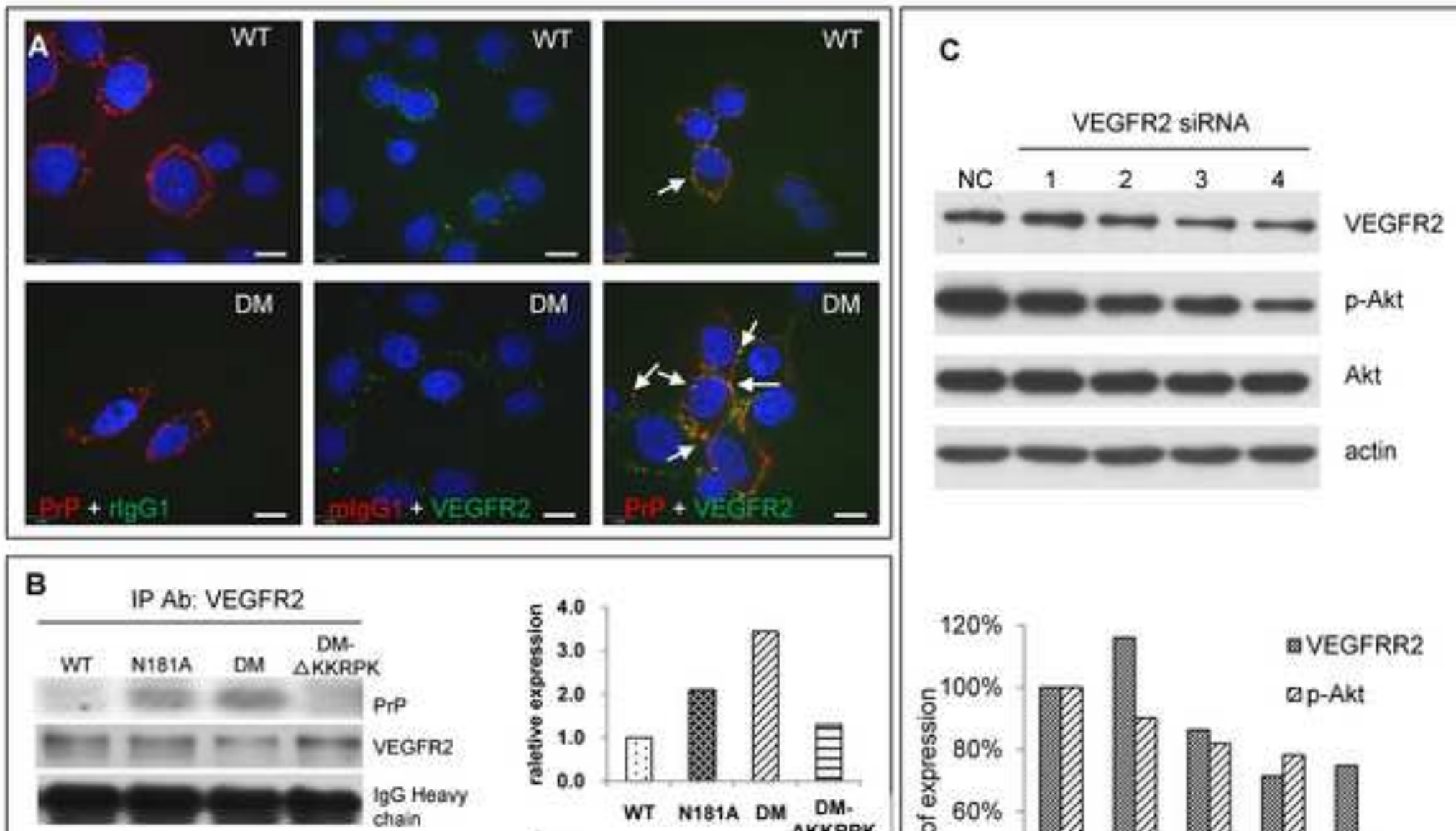
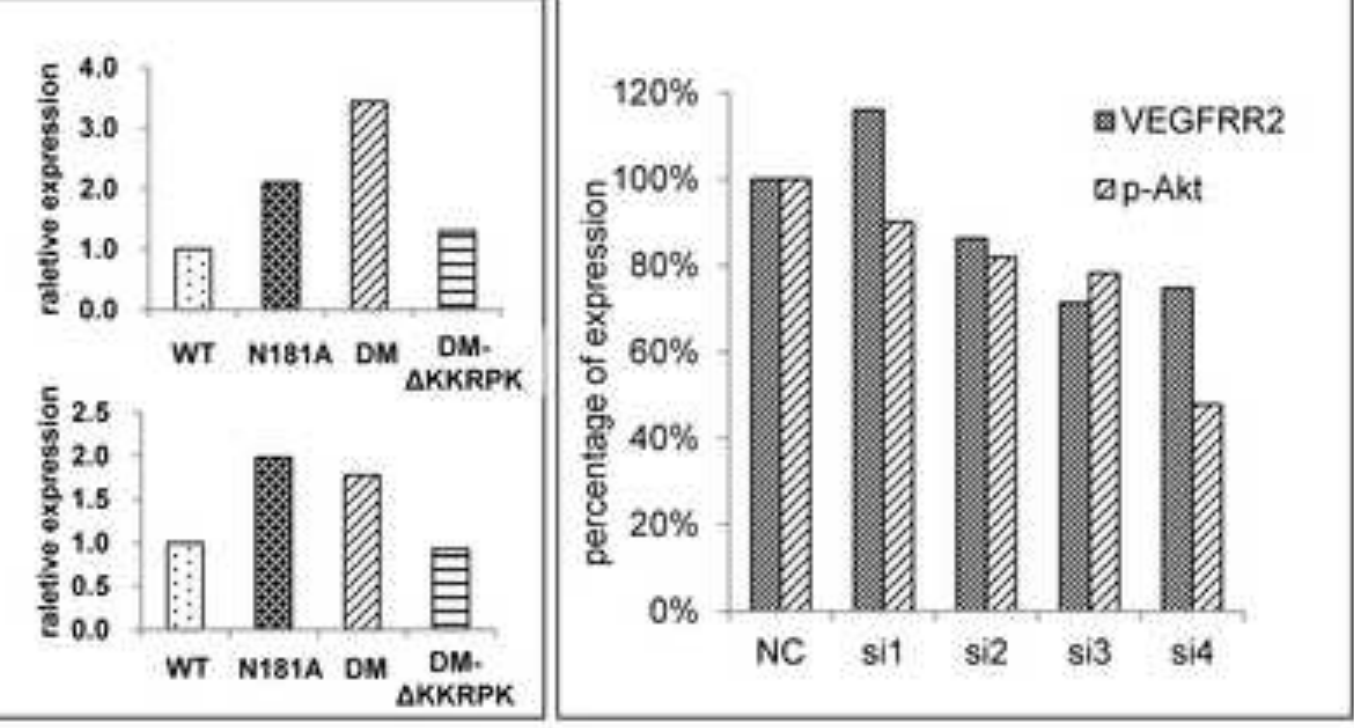
Click here to download high resolution image

Fig 5
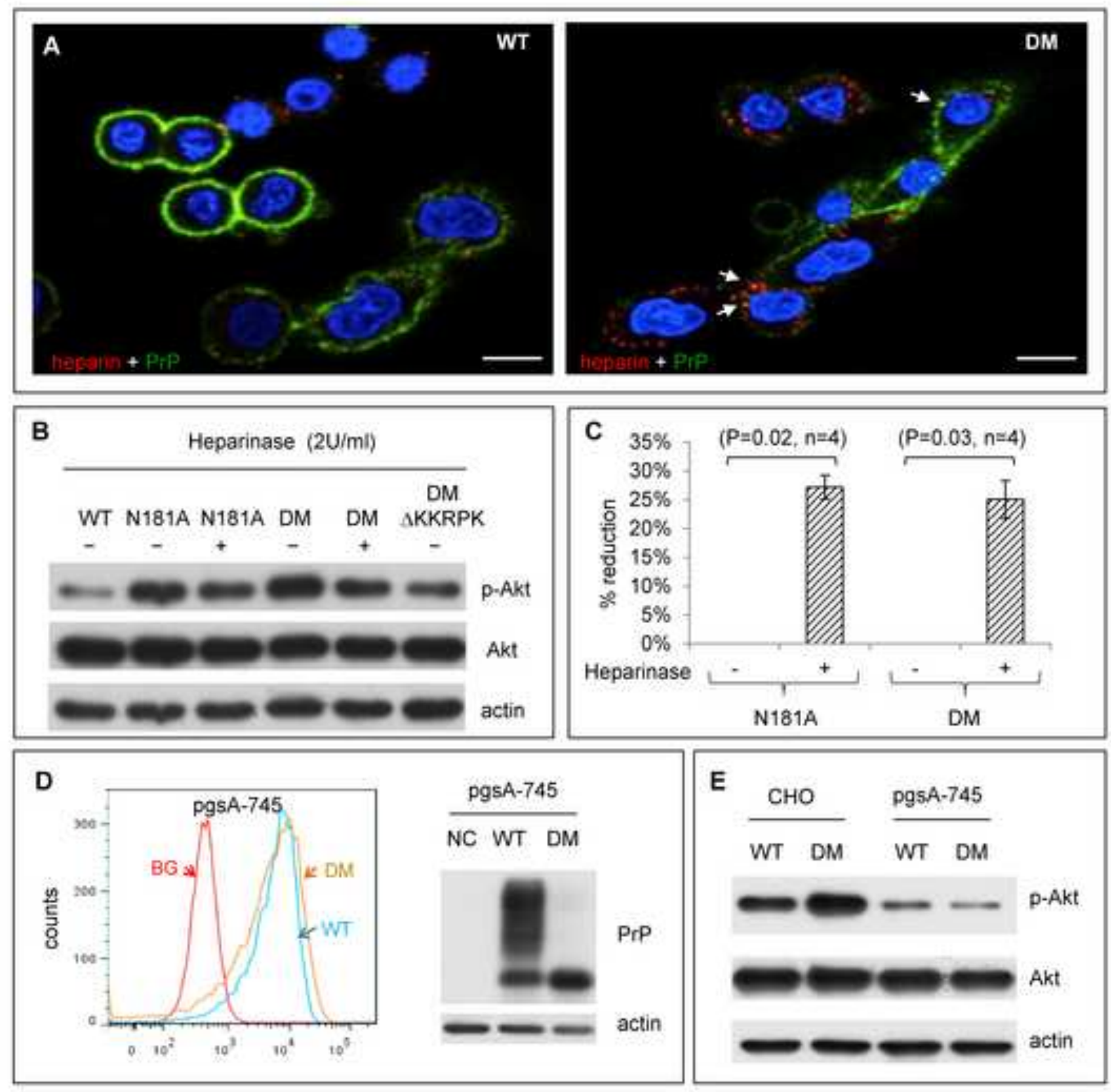
Fig 6
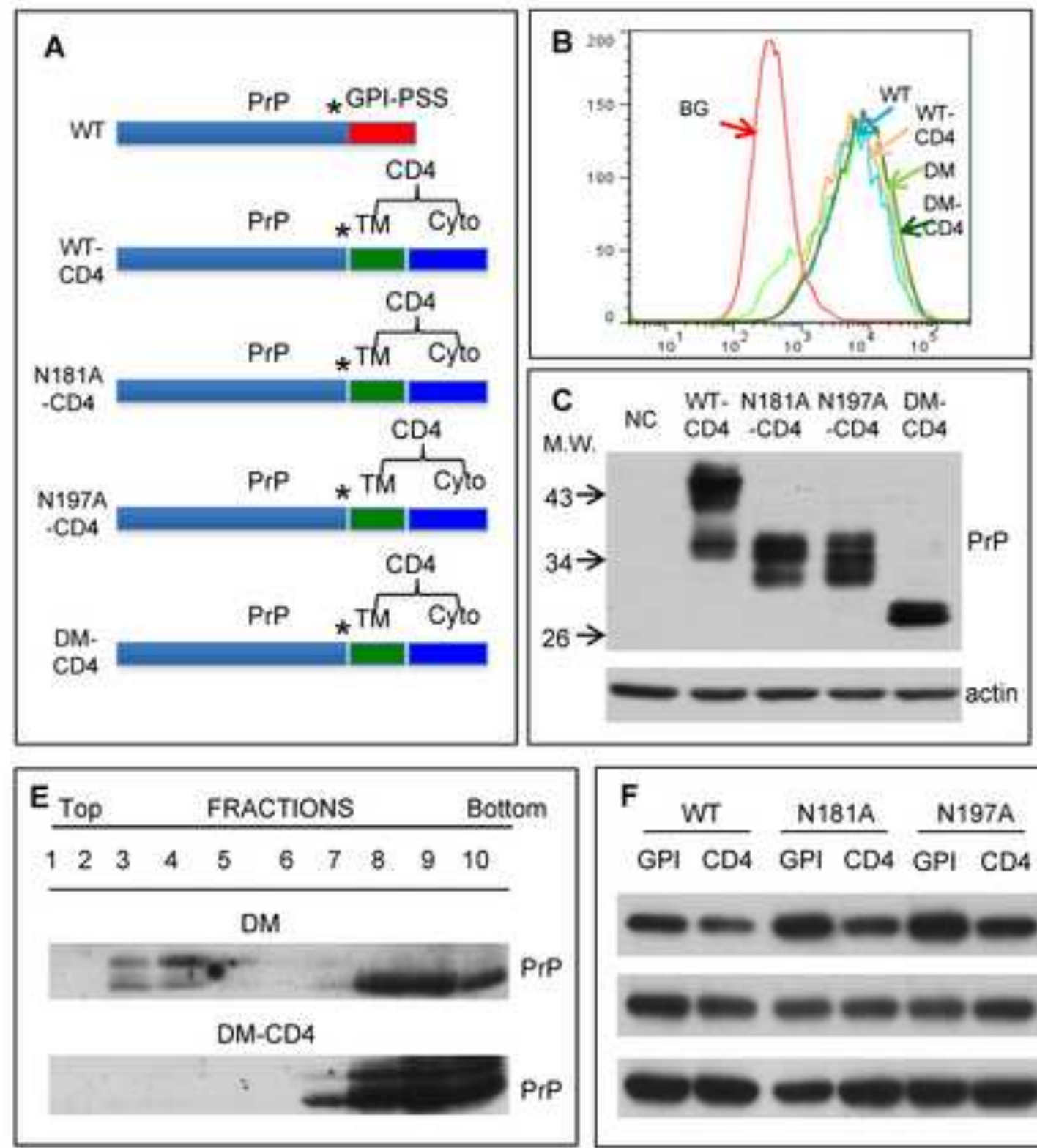

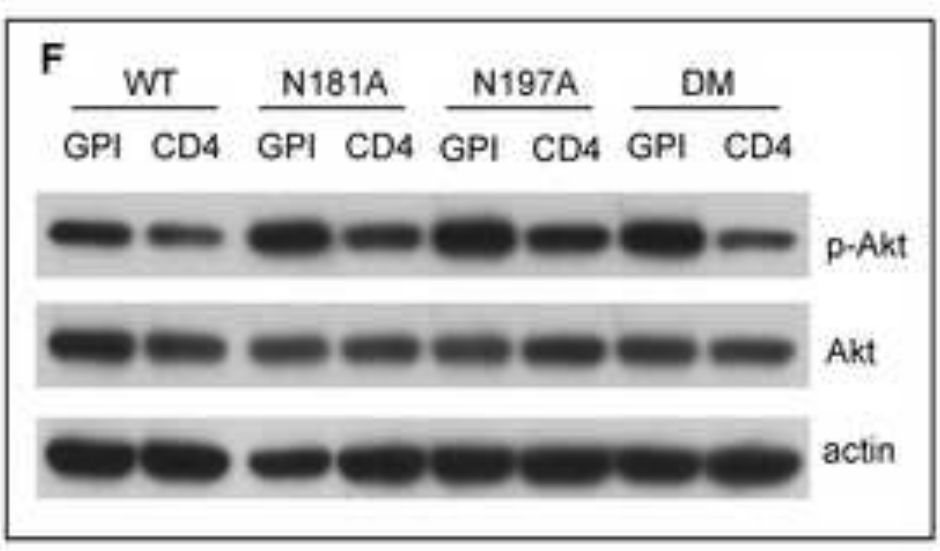

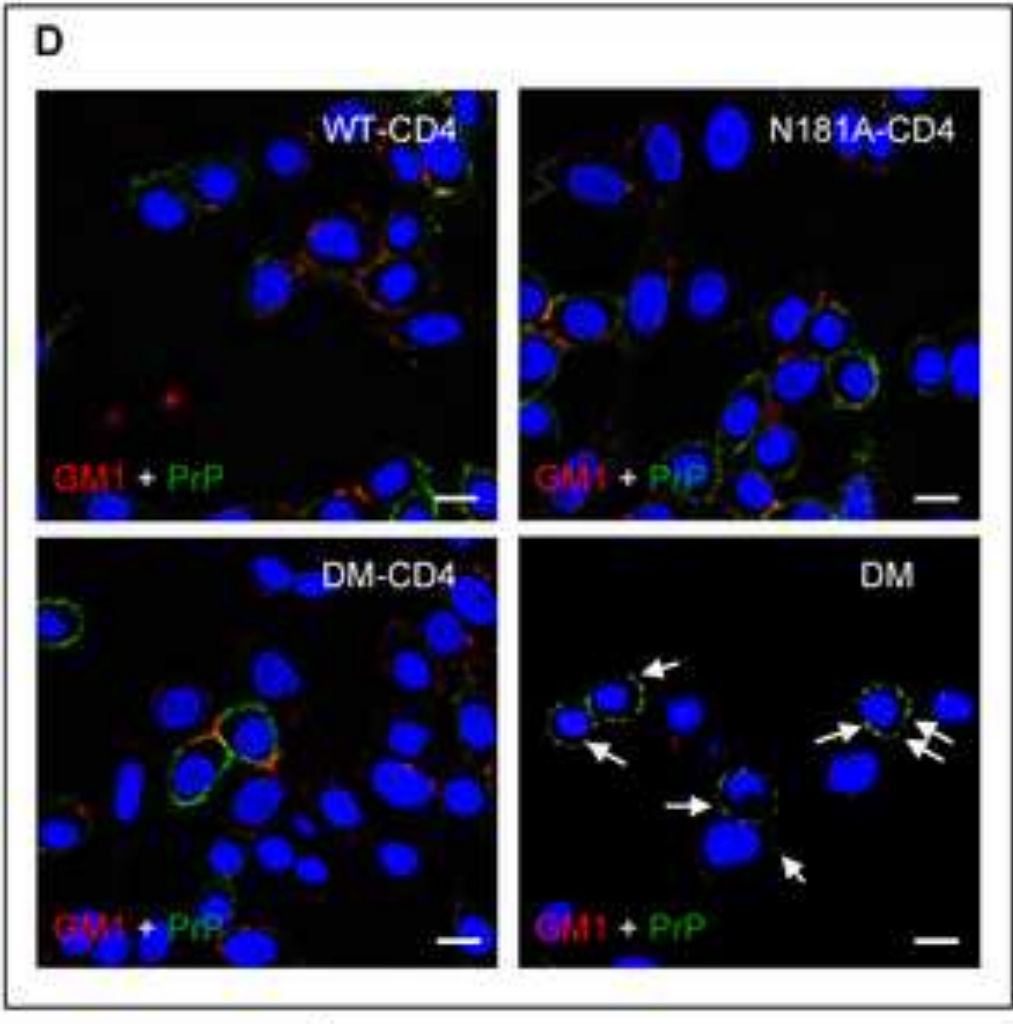

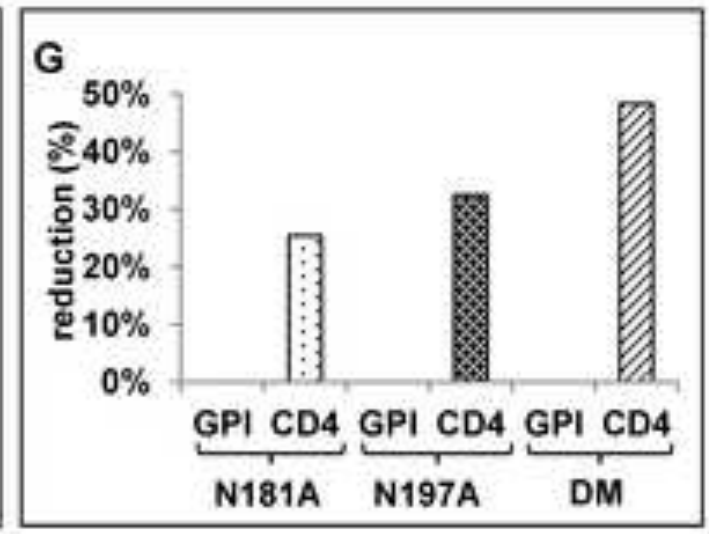


Click here to download high resolution image

Fig 7
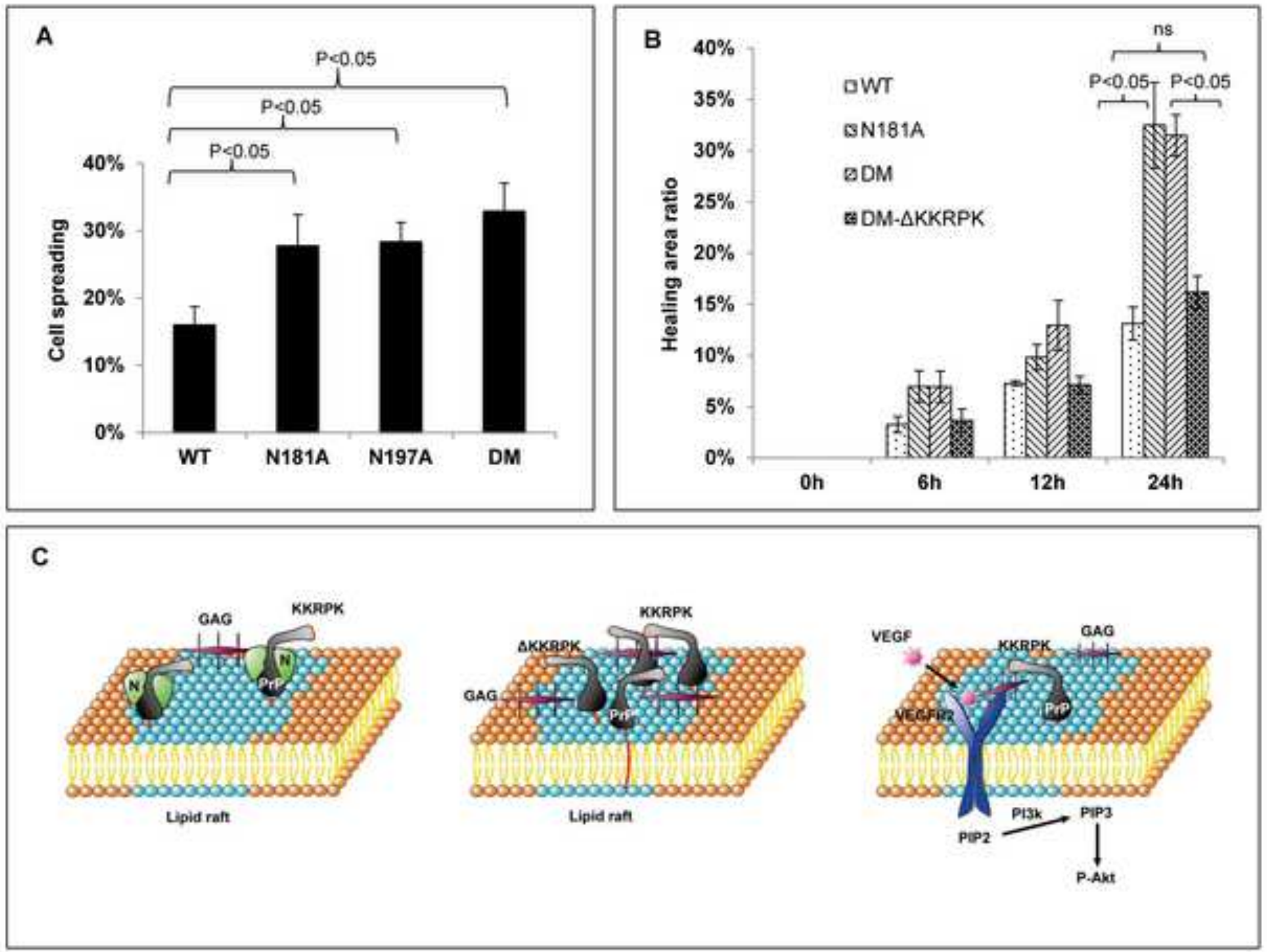
Supplementary Material
Click here to download Supplementary Material: Supplementary data.pdf

Supplementary Material
Click here to download Supplementary Material: Supplementary data.pdf

Supplementary Material
Click here to download Supplementary Material: Supplementary data.pdf

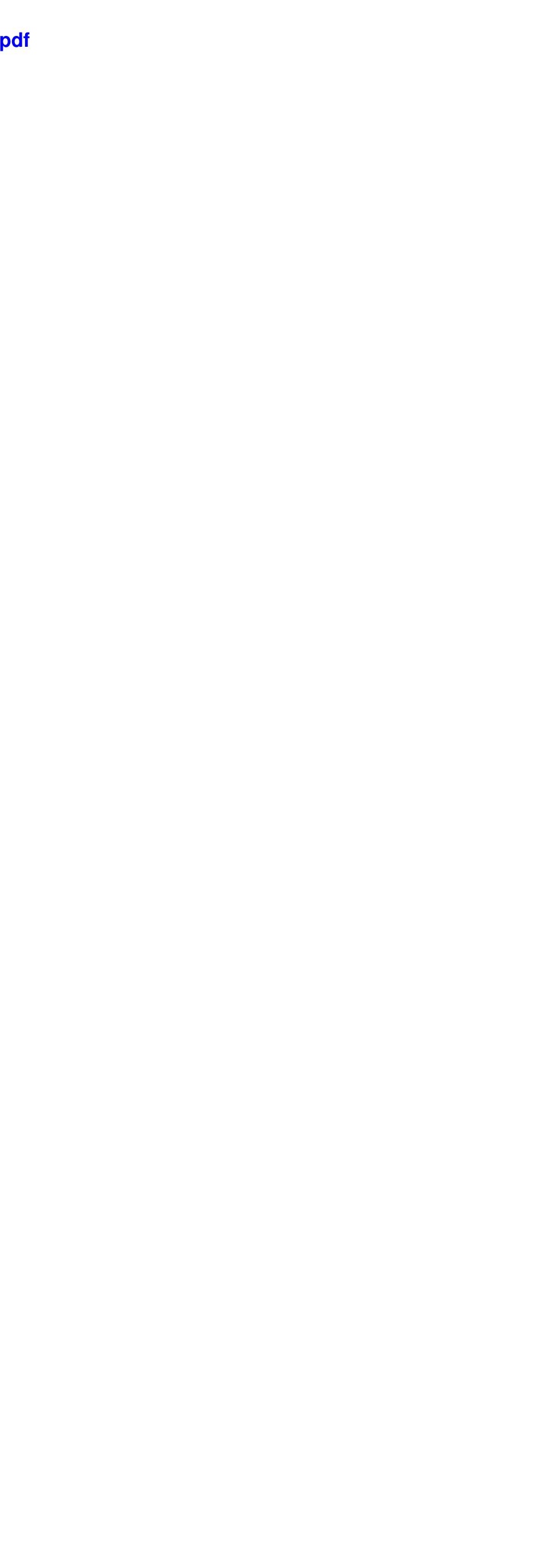

. 